\title{
The BAG
}

Basic Assessment Guide for Human Well-Being
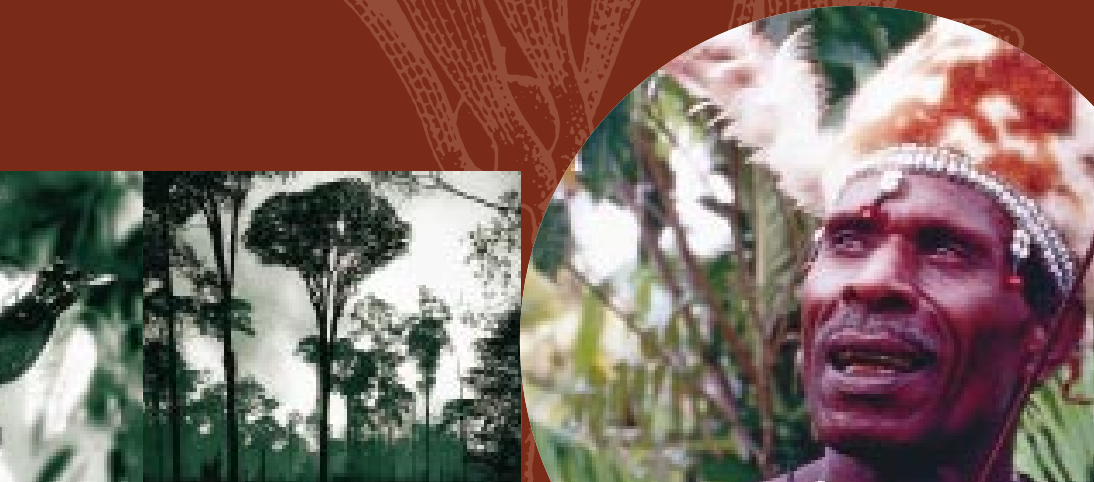

$-$

a
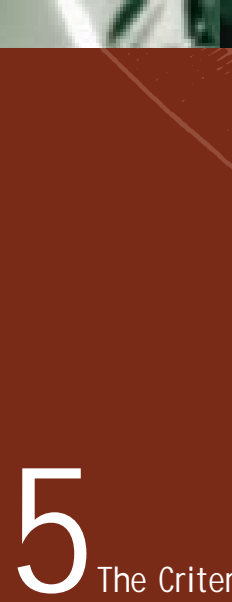

The Giteria \& I ndicators Toolbox Series
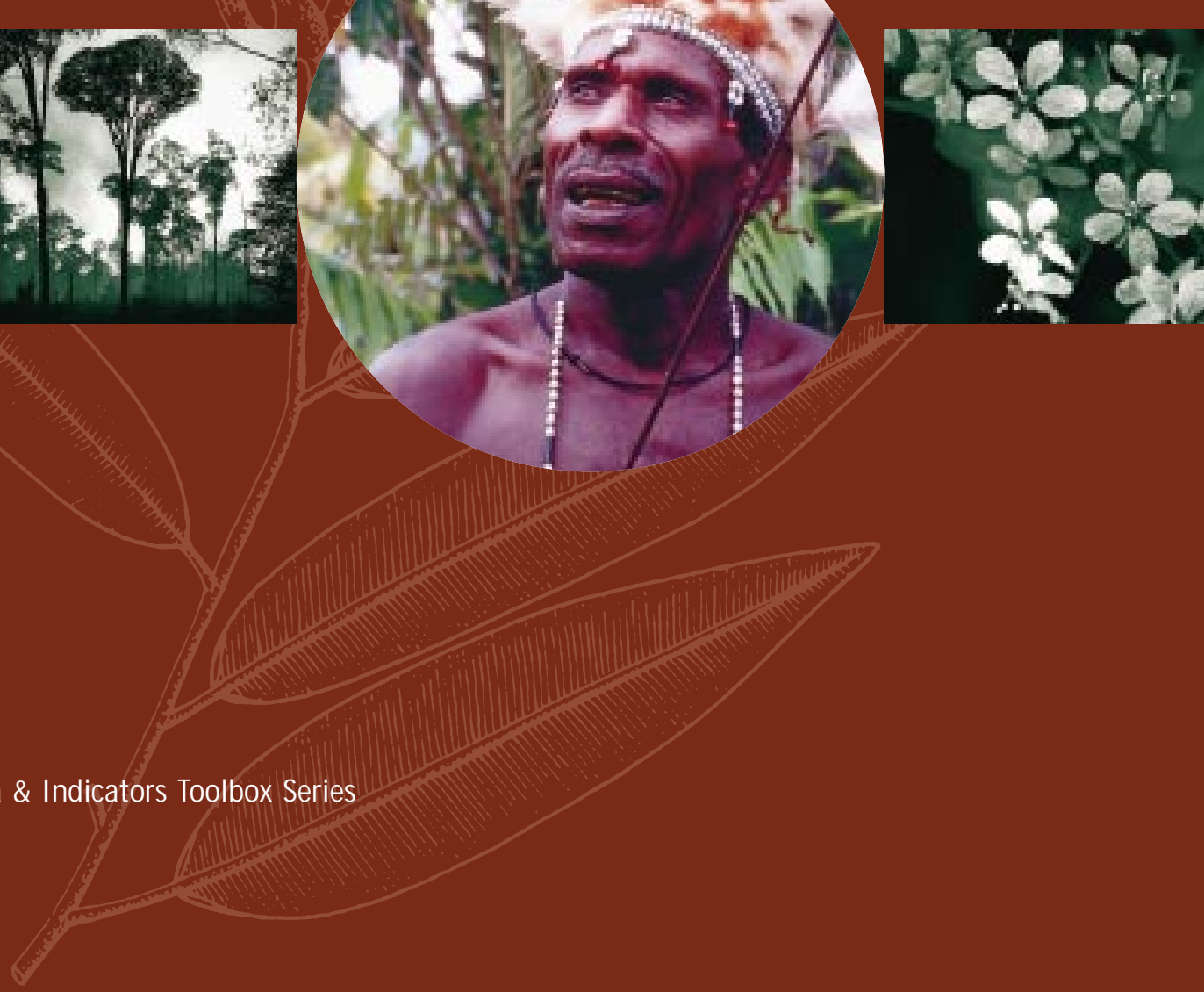
C1999 by Center for International Forestry Research

Designed and Printed by A FT ERH OURS +62 218306819

\section{Photography}

Bird of Paradise by $\mathrm{A}$ lain Compost

Forest burning in background by $\mathrm{A}$ lain $\mathrm{C}$ ompost

A $n$ I rianese holding a bow by A lain Compost

Yellow Flower by Andy Gillison

ISBN : 979-8764-21-8

\section{Published by}

C enter for International Forestry Research (CIFOR)

M ailing address: PO Box 6596 JK PW B, Jakarta 10065, Indonesia

Tel: +62-251-622 622 Fax: +62-251-622 100

E-mail: cifor@cgiar.org

W W W: http://www.cgiar.org/cifor

\section{with support from}

The European Commission

U nder Budget H eading B 7-6201 relating to 'Tropical Forests'

Brussels, B elgium

Deutsche G esellschaft für Technische Zusammenarbeit (G T Z) G mbH

Eschborn, Germany

U nited States A gency for International Development (USA ID)

Washington D.C., U SA 


\section{CQI Toolbox Series}

CQI Tool No. 1 Guidelines for Developing, Testing and Selecting Criteria and Indicators for Sustainable Forest Management

Prabhu, R., Colfer, C.J.P. and Dudley, R.G.

CQI Tool No. 2 The ClFOR Criteria and Indicators Generic Template CIFOR C\&l Team

CQI Tool No. 3

CI MAT (Criteria and Indicators Modification and

Adaptation Tool) (CD-ROM + user manual)

Prabhu, R., Haggith, M., Purnomo, H., Rizal, A., Sukadri, D., Taylor, J.

and Yasmi, $Y$.

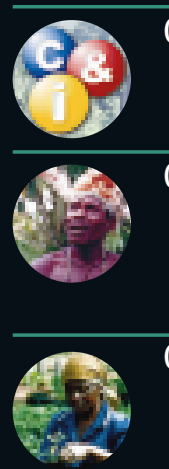

C\&l Tool No. 4

The CIFOR Criteria and Indicators Resource Book Database (CD-ROM + user manual)

McDougall, C., Isbadi, I.R., Santoso, L., Corless, M. and Purnomo, H. (eds.)

\section{C\&I Tool No. 5 \\ The BAG (Basic Assessment Guide for Human Well-Being)}

Colfer, C.J.P., Brocklesby, M.A., Diaw, C., Etuge, P., Günter, M., Harwell, E., McDougall, C., Porro, N.M., Porro, R., Prabhu, R., Salim, A., Sardjono, M.A., Tchikangwa, B., Tiani, A.M., Wadley, R.L., Woelfel, J. and Wollenberg, E.

\section{CQI Tool No. 6 \\ The Grab Bag: Supplementary Methods for Assessing Human Well-Being \\ Colfer, C.J.P., Brocklesby, M.A., Diaw, C., Etuge, P., Günter, M., Harwell, E., McDougall, C., Porro, N.M., Porro, R., Prabhu, R., Salim, A., Sardjono, M.A., Tchikangwa, B., Tiani, A.M., Wadley, R.L., Woelfel, J. and Wollenberg, E.}

\section{C\&I Tool No. 7 Scoring and Analysis Guide for Assessing Human Well-Being Salim, A. and Colfer, C.J.P., with McDougall, C.}

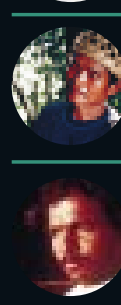

CQI Tool No. 8

Who Counts Most? Assessing Human Well-Being in Sustainable Forest Management

Colfer, C.J.P., Prabhu, R., Günter, M., McDougall, C., Porro, N.M. and Porro, R.

\section{C\&I Tool No. 9 \\ Guidelines for Applying Multi-Criteria Analysis to the Assessment of Criteria and Indicators Mendoza, G.A. and Macoun, P. with Prabhu, R., Sukadri, D., Purnomo, H. and Hartanto, $\mathrm{H}$.}

CQI Tool No. 10 


\section{The BAG \\ Basic Assessment Guide for Human Well-Being}

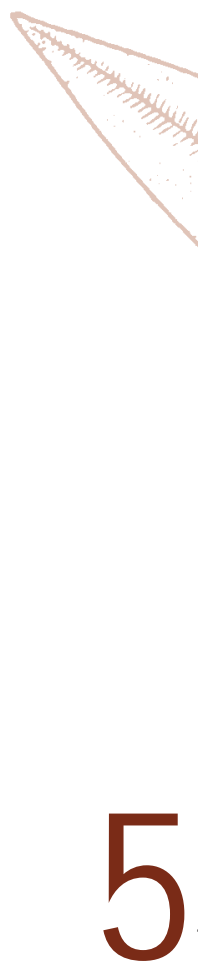

The Criteria \& Indicators Toolbox Series

\section{CIFOR Methods Testing Team}

Carol J. Pierce Colfer, Mary Ann Brocklesby, Chimère Diaw, Priscilia Etuge, Mario Günter, Emily Harwell, Cynthia

McDougall, Noemi Miyasaka Porro, Roberto Porro, Ravi Prabhu, Agus Salim, Mustofa Agung Sardjono, Bertin Tchíkangwa, Anne Marie Tiani, Reed Wadley, J oe Woelfel and Eva Wollenberg 


\section{Table of Contents}

Manuals for Assessing Human Well-Being in Logging Areas $\ldots \ldots \ldots \ldots \ldots \ldots \ldots$

Basic Assessment Guide for Human Well-Being $\ldots \ldots \ldots \ldots \ldots \ldots \ldots \ldots \ldots \ldots$

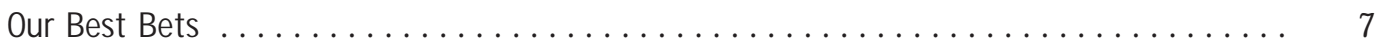

A - Stakeholder Identification $\ldots \ldots \ldots \ldots \ldots \ldots \ldots \ldots \ldots \ldots \ldots \ldots \ldots \ldots \ldots \ldots$

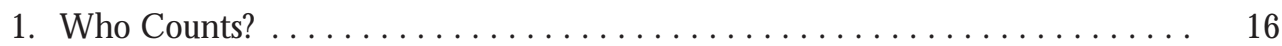

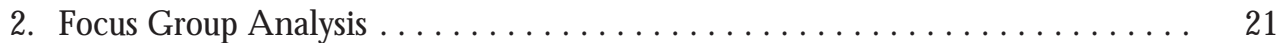

B - Assessment of Security of Intergenerational Access to Resources $(40 \%) \ldots 27$

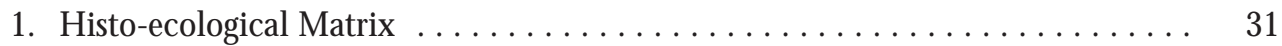

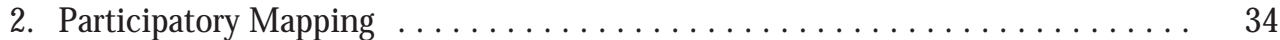

3. A ccess to Resources by $G$ eneration: Pebble Distribution M ethod . . . . . . . . . 38

C - Assessment of Rights and Means to Manage Forests Cooperatively and Equitably (30\%) 45

1. Rights/M eans to $M$ anage: Pebble Distribution $\ldots \ldots \ldots \ldots \ldots \ldots \ldots \ldots$

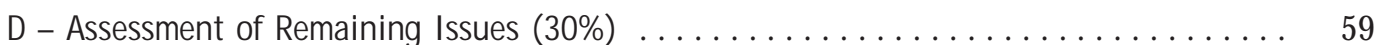

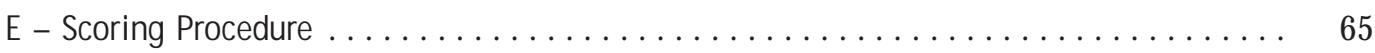

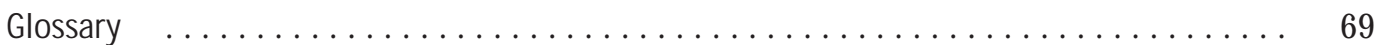

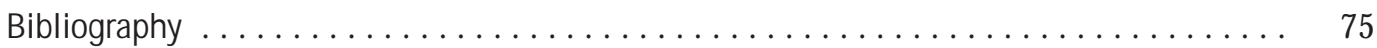


Manuals for Assessing

Human Well-Being in

Logging Areas 
These manuals are designed for use by individuals and organisations wishing to assess the sustainability of a timber operation. This includes a wide variety of potential users (certifiers, private or government timber companies, donor agencies, local people, governments, researchers, etc.). A Ithough the manuals are appropriate for one-time assessments, they can also be used as part of a monitoring program contributing to the improvement of both forest and human conditions. Previous work by CIFOR and others has concluded that the well-being of people living in areas where commercial logging is underway (as well as the maintenance/enhancement of ecological functions) is critical to sustainable forest management, for both pragmatic and ethical reasons.

The challenge of assessing human well-being quickly, easily and reliably prompted CIFO R to initiate a comparative study of social science methods appropriate for use in such assessments (see Colfer 1997). These manuals have been developed, based on results from systematic methods tests in Cameroon, Indonesia, and Brazil, and supplementary work in Trinidad, Gabon and the U nited States. In evaluating sustainable forest management, we assume that assessors will visit timber company base camps and villages, ask pertinent questions of people in the area, and examine available data from the company and local government offices, as well as using the methods here suggested.

The assessment manuals are based on a foundation of criteria and indicators ( or $C \& I$ ), developed by CIFOR teams around the world. These global $C \& I$ are intended to serve as a template against which the sustainability of a given forest (including the well-being of the people living in and around it) can be measured. Ideally, the global set will be adapted to local conditions ( see CIM AT and other components of CIFOR's C\&I 'toolbox' for adaptation tools). 
We focus on certain critical social issues, and assume that ecological and conventional forestry issues will also be addressed in any assessment of sustainability in a given forest. We also recommend including spatial reference data for use by others in possible GIS applications and to facilitate links to other census or household data. In order to facilitate users' ability to come to a decision about whether a particular forest is managed sustainably, we suggest a series of steps and a scoring system that weighs social issues differentially, based on our previous experience.

The best assessments of human well-being are usually conducted by trained social scientists. H owever, because not all parties interested in doing such assessments will necessarily have regular access to such expertise, we have produced two separate manuals. The first, The Basic A ssessment G uide ( T he BA G ), provides a 'cookbook' approach to assessment. It does not represent our ideal. We do, however, believe it can provide guidance in cases where assessors are not qualified social scientists. A ny assessor will need skills in the following areas:

- A $n$ ability and motivation to communicate in an open and comfortable manner with a wide range of stakeholders, including particularly local people and workers;

- A ccess to translators as needed;

- Patience to encourage and solicit information from less visible groups, like women, pygmies, scheduled castes;

- A bility to weigh information in an unbiased manner, particularly eschewing an advocacy role for any particular stakeholder group;

- A wareness of cultural differences and curiosity about local management systems; and 
- Sufficient time in the field to make an assessment (ideally at least a month).

In The BAG, we outline five steps:

1. Identification of relevant stakeholders;

2. A ssessment of security of intergenerational access to resources;

3. A ssessment of rights and obligations to manage forests cooperatively;

4. A ssessment of the health of forests, forest actors and cultures; and

5. A n abbreviated scoring method.

The subsequent discussion of each method provides sampling suggestions and materials required. Every effort should be made to reflect the diversity of stakeholders in the area, with their respective interests, conditions and concerns. This includes women, marginalised ethnic groups, underrepresented age groups, the poor, and others typically ignored. It is al so important to consider the issues of representation, and ensure that you obtain the views of as wide a variety of actors as possible. The importance of using local languages whenever possible cannot be over-stressed. The assessment will be much easier and quicker if you can use a laptop computer. Each method has required materials, but most are inexpensive (paper, pens, pebbles or nuts, large sheets of paper, coloured pens, flipcharts, etc.).

Please read the entire manual before beginning, as earlier steps can contribute to later steps, if you are sensitised and prepared. 
The G rab Bag provides a number of supplementary methods we have found useful. A Ithough they were found valuable by social scientists in our field tests, they have been removed from the 'cookbook' either because of overlap with other methods in the The BA G or because of their difficulty for non-social scientists. Qualified social scientists are understandably likely to prefer selecting methods they consider appropriate in a given situation; indeed, it would be a waste of their expertise to require them to follow a prescribed procedure such as that proposed in T he BAG. The approach advocated in The $G$ rab Bag allows for considerable exercise of professional judgement. O ur intent is that trained social scientists would examine all the methods described and select those that were most appropriate for the area being assessed.

The third, closely related $C \& I$ tool is The Scoring and A nalysis G uide. The section dealing with scoring provides a method for systematising qualitative judgements so that all the $c \& I$ are addressed and evaluated. The section dealing with analysis assumes only minimal computer literacy, and carefully guides the reader through the steps necessary for analysing quantitative data (e.g., from pebble or card sorting methods), beginning with initial data entry through statistical procedures the user may wish to conduct. The explanations assume use of Microsoft Excel and SPSS. 


\section{Basic Assessment Guide for Human Well-Being}


his 'cookbook' is intended for those wishing to assess the sustainability of a forest managed for commercial timber extraction. It recognises the probability that there are people living in and around that timber harvesting area, and that sustainable management will require attention to those people's well-being. It also assumes the existence of separate assessment procedures for ecological and conventional forest management considerations.

Because of our uncertainty about the qualifications of would-be users of this manual, we have aimed it at a person with a bachelor's degree in a natural science or equivalent. It is our hope that in fact assessors will have considerable social science experience as well. W henever this is the case, we hope users will make ample use of the alternatives and supplementary methods provided in $\mathrm{T}$ he $\mathrm{G}$ rab Bag (relevant portions of which we refer to in The BA G).

The BA G is planned to help you collect the information you will need to assess the principles, criteria and indicators listed below. It is our intent that you will

keep these $\mathbf{P}, \mathbf{C} \& \mathbf{I}$ in mind at all times, as you go through the methods outlined below. This will help

\section{This manual outlines five steps:}

1. Identification of relevant stakeholders;

2. Assessment of security of intergenerational access to resources;

3. Assessment of rights and means to manage forests cooperatively and equitably;

4. Assessment of the health of forests, forest actors and cultures; and

5. A scoring method. you make a fair and accurate assessment of local human well-being. 0 ne of your first actions is to enter the Principles, Criteria and Indicators onto a master spreadsheet, ideally on a computer, to which you will refer and add throughout the assessment process (see examples in The Scoring and A nalysis $\mathrm{G}$ uide).

The scoring method is based on a 1-10 
scale, weighted by the importance of the principle. A Scoring and A nalysis $G$ uide is available in the CIFOR C\&I Toolbox to help you in making these qualitative assessments.

Please read through all the steps before beginning your assessment.

We must precede this endeavour with a warning. Social C\&I (and assessing human well-being, more generally) have been and remain the most problematic topic in the attempt to identify useful criteria and indicators. In developing these $C \&$ I, we have taken an iterative approach, starting with a conceptual framework (Colfer et al. 1995), testing $C \& I$ in various locations (Prabhu et al. 1996; Federal M inistry for Environment, Youth and Family 1996; Colfer et al. 1996a,b; 1997a), continually improving on them (Prabhu et al. 1998; C olfer et al. 1997b). W e consider the C \& I we have listed to remain provisional, but to represent an improvement over earlier versions.

We note here several important conclusions we have reached, based on our field tests around the world:

1. The variation across sites, among proposed social $C \& I$, was greater than the variation among ecological or forestry-related $C \& I$ - reflecting both human variety and methodological difficulty in making assessments of human well-being.

2. A greement was greater at the principle and criterion levels than at the indicator or verifier levels, again reflecting the many manifestations of human well-being and the probability that indicators and verifiers may always require local adjustment.

3. Each method we have tested has required some 'tinkering' at 
the field level (e.g., language, stakeholder identification, relevant forest products) and we believe this cannot be avoided.

O ur definition of sustainability includes maintaining or enhancing human well-being and ecological functioning. The scoring provided in this manual is intended to provide one third of the total score in the assessment of the timber operation's sustainability. This score on human wellbeing is intended to be integrated with scores on ecological functioning and on conventional forestry operations (see CIFOR's Toolbox for other relevant manuals).

We have opted in most methods for sample sizes that do not vary by size of population. This is because we assume a short period of fieldwork and consider representation of local human diversity to be more significant than statistical concerns. If time and resources permit, however, increasing sample sizes for larger populations (proportional sampling) would be preferable.

A $n$ ideal (future) manual would provide a specific method for assessing each of the indicators identified as important, which, in turn, could be summed to provide a score for each criterion. We have not yet reached that stage. Instead, we present methods that provide data that can contribute to your emerging understanding of the issues identified in the $C \& I$ - particularly the criteria, since these have been shown to be more widely applicable than specific indicators. We ask assessors to make informed estimates, based on The Scoring and $A$ nalysis $G$ uide, of each indicator, and combine these for the final sustainability score. Considerable human judgement remains important in the use of this manual and in assessment of human well-being, in general. 
Our Best Bets 


\section{P1 Forest management maintains or enhances fair intergenerational access to resources and economic benefits}

C1.1 Local management is effective in controlling maintenance of and access to the resource. ${ }^{1}$

I1.1.1 Ownership and use rights to resources (inter- and intragenerational) are clear and respect preexisting claims.

11.1.2 Rules and norms of resource use are monitored and enforced.

11.1.3 Means of conflict resolution function without violence.

11.1.4 Access to forest resources is perceived locally to be fair.

I1.1.5 Local people feel secure about access to resources.

C1.2 Forest actors have a reasonable share in the economic benefits derived from forest use.

11.2.1 Mechanisms for sharing benefits are seen as fair by local communities.

1 1.2.2 Opportunities exist for local and forest-dependent people to receive employment and training from forest companies.

I1.2.3 Wages and other benefits conform to national and/ or International Labour Organisation (ILO) standards.

11.2.4 Damages are compensated in a fair manner.

11.2.5 The various forest products are used in an optimal equitable way.

C1.3 People link their and their children's future with management of forest resources.

11.3.1 People invest in their surroundings (e.g., time, effort, money).

11.3.2 Outmigration levels are low. ${ }^{2}$

11.3.3 People recognise the need to balance numbers of people with natural resource use.

11.3.4 Children are educated (formally and informally) about natural resource management.

I1.3.5 Destruction of natural resources by local communities is rare.

I1.3.6 People maintain spiritual or emotional links to the land.

1 This criterion is obviously very closely connected with criteria addressed from ecological and formal 'forest management' perspectives.

2 Indicators 1.3.2 and 3.1.2 contain a potential contradiction. Low levels of outmigration (I1.3.2) indicate that people link their and their children's futures to maintaining the forest; yet recognising the need to balance numbers of people with natural resource use (13.1.2) may lead them to favour outmigration. This contradiction would likely occur when conditions are deteriorating. 


\section{P2 Concerned stakeholders have acknowledged rights and means to manage forests cooperatively and equitably}

C2.1 Effective mechanisms exist for two-way communication related to forest management among stakeholders.

I2.1.1 $>50 \%$ of timber company personnel and forestry officials speak one or more local language, or $>50 \%$ of local women speak the national language.

12.1.2 Local stakeholders meet with satisfactory frequency, representation of local diversity, and quality of interaction.

12.1.3 Contributions made by all stakeholders are mutually respected and valued at a generally satisfactory level.

C2.2 Local stakeholders have detailed, reciprocal knowledge pertaining to forest resource use (including user groups and gender roles) as well as forest management plans prior to implementation.

12.2.1 Plans/maps showing integration of uses by different stakeholders exist.

12.2.2 Updated plans, baseline studies and maps are widely available, outlining logging details like cutting areas and road construction, and include temporal aspects.

12.2.3 Baseline studies of local human systems are available and consulted.

12.2.4 Management staff recognises the legitimate interests and rights of other stakeholders.

12.2.5 Management of NTFP reflects the interests and rights of local stakeholders.

C2.3 Agreement exists on rights and responsibilities of relevant stakeholders.

12.3.1 Level of conflict is acceptable to stakeholders. 


\section{P3 The health of forest actors, cultures and the forest is acceptable to all stakeholders}

C3.1 There is recognisable balance between human activities and environmental conditions.

13.1.1 Environmental conditions affected by human uses are stable or improving.

13.1.2 Inmigration and/or natural population increases are in harmony with maintaining the forest.

C3.2 The relationship between forest management and human health is recognised.

13.2.1 Forest managers cooperate with public health authorities regarding illnesses related to forest management.

13.2.2 Nutritional status is adequate among local populations (e.g. children's growth conforms to international standards of height for weight; infant and $<5$ year mortality levels are (ow). ${ }^{3}$

13.2.3 Forest employers follow ILO work and safety conditions and take responsibility for the forestrelated health risks of workers.

C3.3 The relationship between forest maintenance and human culture is acknowledged as important.

13.3.1 Forest managers can explain links between relevant human cultures and the local forest.

13.3.2 Forest management plans reflect care in handling human cultural issues.

13.3.3 There is no significant increase in signs of cultural disintegration.

3 The fact that this indicator is not necessarily related to its criterion is one example of the shortcomings in this third principle, due to the absence - in contrast to the first two principles - of systematic field testing. 


\section{Stakeholder Identification ${ }^{4}$}

4 In The Grab Bag, we provide two additional methods to help in making this assessment: Wollenberg's (1997) matrices, and Woelfel's CatPac neural network analysis. 
he first step in any assessment procedure related to human well-being in forest managed for timber is to identify the relevant stakeholders. Holding a timber company in A frica responsible for the well-being of green consumers in the U S does not make sense, yet the idea that timber companies share some responsibility for the well-being of people in their immediate areas is widely accepted. The correct identification of such 'forest actors' is necessary to make the assessments subsequently outlined in this manual.

Here, we propose a two-stage process for identifying relevant stakeholders in sustainable forest management. The first phase 5 is called the 'W ho C ounts M atrix'. It provides a simple way of drawing the line between those stakeholders on which a company needs to focus its attention and those on which it does not. The second method is called 'Focus Group A nalysis' (Mt. Cameroon Project 1996). Focus Group A nalysis identifies whom people in the area consider important and how.

5 This order can be reversed if the assessor feels unable to identify the repertoire of stakeholders. But in general, we have found the rough and ready identification needed for the Who Counts Matrix, to be fairly easily developed, with a little help from people on site. 


\section{1 - WHO COUNTS? ${ }^{6}$}

\section{PURPOSE}

To identify a small set of stakeholders closely connected to the forest who need to be involved in forest assessment and management. Several sets of information will be collected about these forest actors, for use in assessing local human well-being.

\section{METHOD}

This method involves creating a matrix. A cross the top are listed the stakeholders initially identified as important. This can be based on prior knowledge, interviews with knowledgeable parties, existing literature. By talking informally with local officials and community members, you can improve your understanding of possible stakeholders. A long the left hand side are listed seven dimensions. Proximity, preexisting claims, dependency, poverty, local knowledge, culture/forest integration and power deficit - defined below in boxes. ${ }^{7}$ These dimensions reflect the importance of the forest to the people.

\section{SCORING}

O nce the stakeholders and user groups have been listed across the top of the page, score each one on the degree to which each dimension generally applies to them:

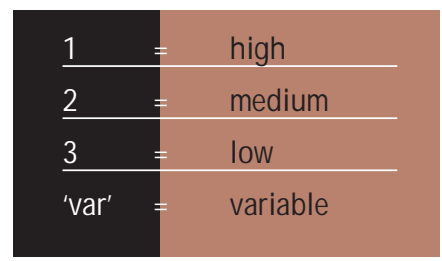

6 This method is described in more detail in Colfer et al. (1999).

7 There has been some discussion about combining 'local knowledge' and 'forest/ culture integration'. Although we have not done so here, it may be sensible in some contexts. 'Poverty' has been deleted in some methods tests; and a 'conservation ethic' has been considered as a possible dimension for inclusion. 
The scoring process involves making an estimate based on your early observations and the views of people you meet. The mean scores for each column (excluding 'variable' scores) is computed across the bottom of each table. The cutoff point for defining who counts, in our experience, has been a score of $<2$. Discuss these estimates with others and revise accordingly.

The ease of the rest of the methods presented in this booklet depends partly on having a fairly small number of groups who count (hereafter called 'forest actors') - ideally between three and seven. Examine your set of user group/stakeholder categories critically to see if you can safely combine any of them and if you have accounted for the most important human variation. Make a final selection of forest actors whose well-being you will proceed to assess. 


\section{SAMPLE FORM}

\section{Example from Côte d'Ivoire}

\section{STAKEHOLDERS}

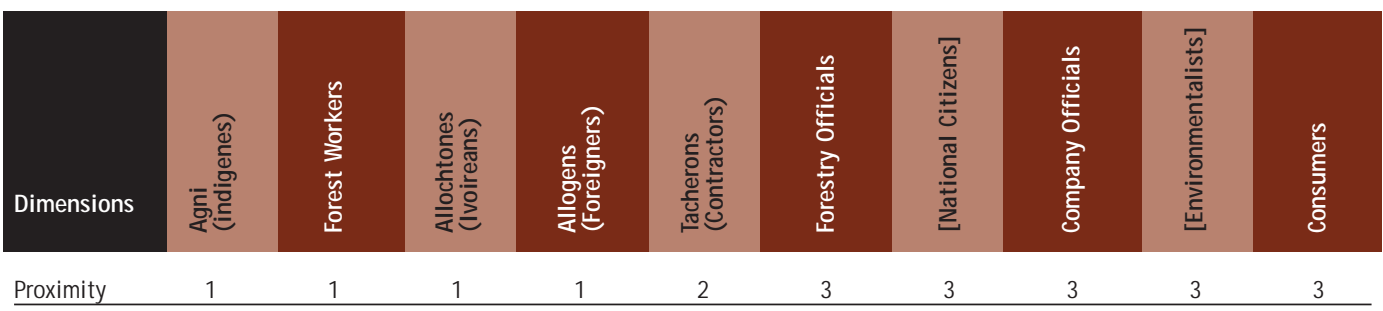

Pre-existing

\begin{tabular}{lllllllllll} 
rights & 1 & var & 2 & 3 & var & 2 & 2 & 3 & 3 \\
\hline Dependency & 1 & 1 & 1 & 1 & 2 & 1 & 3 & 3 \\
\hline Poverty & 1 & 1 & 1 & 1 & 2 & 3 & var & 3 \\
\hline
\end{tabular}

Indigenous

knowledge

1

2

2

2

2

3

3

Culture/

Forest link

\begin{tabular}{lcccccccccc} 
Forest link & 1 & 2 & 2 & 2 & var & 3 & 2 & 3 & 2 \\
\hline Power deficit & 2 & 1 & 1 & 1 & 2 & 3 & var & 3 & 3 & \\
& & & & & & & & & & \\
VALUE & 1.14 & 1.33 & 1.43 & 1.57 & 2.00 & 2.57 & 2.60 & 3.17 & 2.83
\end{tabular}

\section{VALUE}

\begin{tabular}{|c|c|c|c|c|c|c|c|c|c|c|}
\hline Forest link & 1 & 2 & 2 & 2 & var & 3 & 2 & 3 & 2 & 3 \\
\hline Power deficit & 2 & 1 & 1 & 1 & 2 & 3 & var & 3 & 3 & var \\
\hline VALUE & 1.14 & 1.33 & 1.43 & 1.57 & 2.00 & 2.57 & 2.60 & 3.17 & 2.83 & 3.00 \\
\hline
\end{tabular}

\begin{tabular}{lcccccccccc} 
Forest link & 1 & 2 & 2 & 2 & var & 3 & 2 & 3 & 2 & 3 \\
\hline Power deficit & 2 & 1 & 1 & 1 & 2 & 3 & var & 3 & 3 & var \\
VALUE & 1.14 & $\mathbf{1 . 3 3}$ & $\mathbf{1 . 4 3}$ & $\mathbf{1 . 5 7}$ & $\mathbf{2 . 0 0}$ & $\mathbf{2 . 5 7}$ & $\mathbf{2 . 6 0}$ & $\mathbf{3 . 1 7}$ & $\mathbf{2 . 8 3}$ & $\mathbf{3 . 0 0}$
\end{tabular}

\begin{tabular}{lcccccccccc} 
Forest link & 1 & 2 & 2 & 2 & var & 3 & 2 & 3 \\
\hline Power deficit & 2 & 1 & 1 & 1 & 2 & 3 & var & 3 & 3 \\
& & & & & & & & & \\
VALUE & 1.14 & 1.33 & 1.43 & 1.57 & 2.00 & 2.57 & 2.60 & 3.17 & 2.83
\end{tabular}

1 = high, 2 = medium, 3 = low 


\section{Proximity to Forest}

By proximity, we mean simply closeness to the forest. We are acknowledging the potential for people living near the forest to have a significant impact on it. People with easy access to the forest can be beneficially involved in forest management. People who perceive themselves to be unjustly excluded from nearby forest also have the ability, directly or indirectly, to degrade it. Some researchers have suggested including emotional, as well as physical, proximity in this dimension, since in some cases those who care about a forest act upon it (sometimes from afar).

\section{Pre-existing Rights}

In many places, forests under threat are subject to conflicting land claims, indeed even to conflicting paradigms of what land ownership and use should mean. Sometimes, communities that have occupied a given area for decades, centuries or even millennia, have had their traditional rights usurped or severely compromised in recent times. If there are such people in or near a forest, recognition of their rights is important both ethically and pragmatically. J ustice requires that people's rights to the forest be acknowledged and respected. From a purely practical point of view, perceived injustice can lead to a variety of ills from disregard of forest policies to increases in conflict, vandalism and violence.

\section{Dependency}

In many forested areas, there are communities which are dependent on the forest for a range of goods and services. The people may hunt, fish, gather foods, medicines and fibres, or practice agroforestry. It is also common for such people to have few realistic alternatives to their existing way of life (recognising that this can change, of course). The needs of people whose livelihoods depend on the forest must be incorporated into sustainable forest management. Ethically, people's access to food is an important consideration. Practically, people whose children are hungry because they are denied access to the forest may not respect forest borders.

\section{Poverty}

This concept carries with it many pitfalls because of different meanings around the world. In this context, our concern is to differentiate those whose use of the forest carries survival implications (such as a Dayak or transmigrant farmer in Kalimantan; or a Bakolo pygmy or Bantu farmer in Cameroon) from those whose use of the forest simply increases an already adequate income (such as a timber tycoon or a forestry official). 


\section{Local Knowledge}

People who have lived in forested areas often have unique and useful knowledge based on their long-term, local experience. Such knowledge may pertain to animals and their behaviour, plants and their management, uses of various products, techniques for processing forest products, etc. Local knowledge is valuable for its own sake, given our comparative ignorance about the ecology of forests (particularly tropical forests). It can also serve an important function in incorporating local people actively and beneficially in forest management. External recognition and use of their knowledge can serve as tools for empowering local people and enhancing communication and cooperation between them and other forest managers.

\section{Forest/ Culture Integration}

Cultures (or ways of life) - including those of forest communities - tend to be intimately linked to their environments. There may be sacred sites within the forest, symbolic systems which give meaning to life and are intimately tied to people's sense of self, security functions of forest plants during times of scarcity, and myriad other connections. Insofar as a people's way of life is integrated with the forest, the continuation of their culture is jeopardised by forest loss and the human repertoire of cultural diversity is impoverished. Human well-being is typically adversely affected by cultural disintegration.

\section{Power Deficits}

In many areas, the people who live in or near the forest have comparatively little power, vis-à-vis other stakeholders. Power may be based on education, wealth, connections to government, or locally recognised authority. Where a local power deficit does exist, it may adversely affect the forest, since the people will not have the means to protect their resources from outside forces. Both environmental degradation and reduced human welfare may result. Another element in the power issue pertains to whose knowledge 'counts'. The common silencing, or muting, of some people's voices has a number of potentially dangerous effects, such as reducing their ability and willingness to participate in cooperative forest management or reducing formal managers' access to useful knowledge. 


\section{2 - FOCUS GROUP ANALYSIS}

PURPOSES

- To provide systematic confirmation of local stakeholders and user groups;

- To assess local perceptions of the distribution of power among groups; ; and

- To gain a qualitative overview of forest use and trends in the area.

\section{MATERI ALS}

A dapt the form provided below to your local context; and prepare enough copies for each meeting you plan. Flipcharts and large paper are desirable. Some researchers have used tape recorders (but transcription time is considerable).

\section{PARTICI PANTS}

Identification of stakeholders is part of the iterative assessment process. Filling in the W ho Counts $M$ atrix is a probable first step. By talking informally with local officials and community members, you can improve your understanding of possible stakeholders. For a given community, plan to bring together, at least, three groups of, perhaps, ten people each. Separate groups might be men/women, elders/adults/ youth, farmers/herders/hunter-gatherers, timber company workers/local community members/forestry officials, or others, depending on locally significant differences among people and patterns of interaction. It is important to remember that, in many groups, women are not willing to speak in front of men, in which case separate groups are necessary. Women's input is needed and, typically, requires special attention. For more ideas on covering community variation, see Wollenberg's matrix in

8 This additional information on power may be important for confirming the conclusions from the 'Who Counts Matrix'. Evaluation of power differences has been particularly difficult. 
The G rab Bag. It will probably not be possible to cover all the important social differences in this one method. ${ }^{9}$

\section{METHOD ${ }^{10}$}

The focus group is organised around a series of questions and/or issues. These questions and issues directly feed into the framework provided in the two attached forms (identified in brackets after each question/issue). A Ithough slightly expanded versions of the forms presented here were found useful in Mt. Cameroon (Brocklesby et al. 1997), other researchers have simplified them, and this may be desirable in your locations. ${ }^{11}$

We suggest the following issues/questions, but again local conditions can vary and you may need to adapt them:

- List the groups most involved in forest use and management and rank them in descending order of importance. [I mpacts, power forms]

- W hy are these people considered important? [Impacts form]

- W hat are the important activities (harmful/beneficial for the

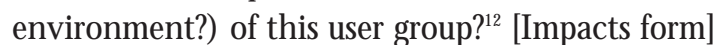

- W hat would be the impacts of inclusion or exclusion of these people in formal forest management? [I mpacts form]

- State their interest and rank it, showing the direction of future change. [Interests/power forms]

9 Tchikangwa et al. (1998) selected local communities and conservation project personnel. They were then able to get a clear view of the different perceptions of these groups (cf. Criterion 2.3, 'Agreement exists on rights and responsibilities of relevant stakeholders').

10 We draw on IUCN 1997:132-3 and Brocklesby et al. (1997) here. The method received additional testing by Diaw et al. 1998; MCDougall 1998; Porro and Porro 1998; Sardjono et al. 1997; Tchikangwa et al. 1998; and Tiani et al. 1997.

11 McDougall (1998), for instance, found differentiating between importance and power to be difficult in the field. She also found activities and interests to be difficult to separate.

12 Regulation of hunting, definition of boundaries, monitoring mechanisms would be examples of activities with positive impacts; cutting down a tree to collect its fruit, electric fishing, harvesting unsustainably are examples of activities with a negative impact. 
- Rank their power and indicate the direction of future change. [Interests/power forms]

W hen the group meets, explain to them the purposes of the meeting. These issues are typically sensitive and must be handled with care.

If possible, one person should moderate and another take notes. If this is impossible, a tape recorder is one alternative, but Tchikangwa et al. (1998) found transcription time to be a significant 'downside' to this approach. McDougall (1998) and Porro and Porro (1998) recommend flipcharts, feeling that this gave the people a feeling of ownership and involvement in a shared product. It may be important to use drawings on the flipcharts, rather than words, when there are significant numbers of illiterate people in the groups. Diaw et al. (1998) found the process to be an empowering one for local people.

Good facilitation skills are important in conducting the meeting. The ability to control overtalkative participants and stimulate silent ones is critical and can make the difference between a successful and an unsuccessful Focus Group. A session should only last about an hour, definitely no more than two, and should be enjoyable for participants.

ANALYSIS AND SUBSEQUENT USE

Carefully review your notes after the meeting, as you fill in the forms (on impacts and power), as adapted to your context. A fter filling in the forms, based on your discussions, check with some of the participants to verify your understanding of their intent. Tchikangwa et al. (1998) recommend filling in the forms during the group sessions, if time is limited.

This process should give you a good understanding of major actors in the local environment, and some hints about trends in this area. 


\section{Strengths ( + ) and Weaknesses (-) of Focus Group Analysis}

+ $\quad$ Participants (especially vulnerable groups) may feel more free to talk when they are in a group of similar people.

$+\quad$ Group interaction enriches the quality and quantity of information provided.

$+\quad$ Different points of view between different groups in the community can be identified.
- $\quad$ The facilitator needs to be able to stimulate group interaction during the interview.

- $\quad$ The tool entails some interpretation of participants' responses by the person completing the analysis.

- $\quad$ People may be reluctant to share their opinions with an outsider and some responses may not be entirely accurate. Establishing trust in the facilitator and within the group at the beginning of the process is usually needed to collect valid and complete information.

Excerpted from IUCN 1997. 
SAMPLE FORM

\section{Focus Group Analysis Form}

[ $\mathrm{m} p$ a c t s ]

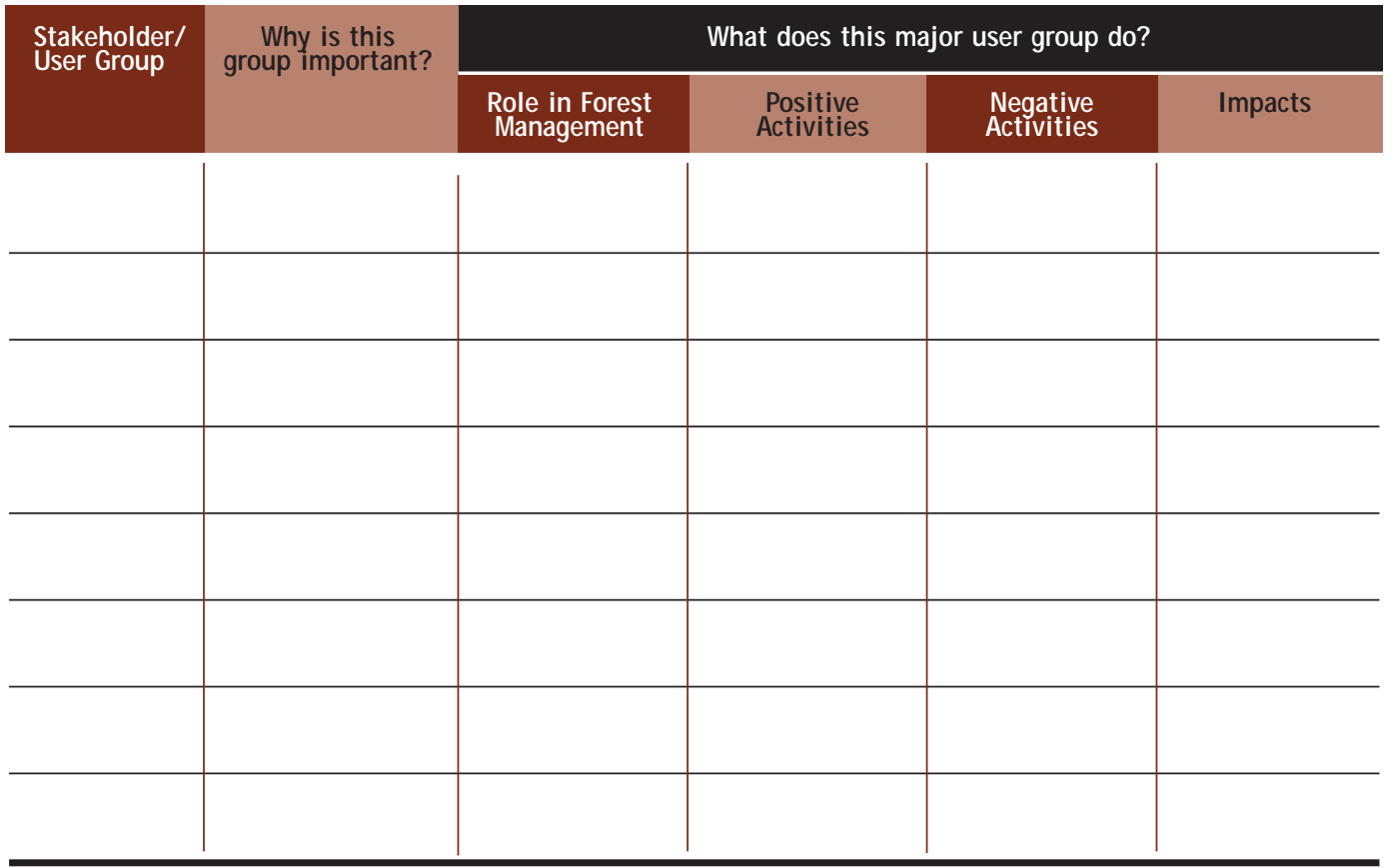




\section{SAMPLE FORM}

Focus Group Analysis Form

[ I n t e rest s/ P o wer ]

\begin{tabular}{|c|c|c|c|c|c|c|c|}
\hline \multirow{2}{*}{$\begin{array}{l}\text { Stakeholder/ } \\
\text { User Group }\end{array}$} & \multicolumn{4}{|c|}{ Interest } & \multicolumn{3}{|c|}{ Power } \\
\hline & Stated & Rank & Change & Reasons & Rank & Change & Reasons \\
\hline Pygmies & $\begin{array}{l}\text { Access to } \\
\text { hunting areas } \\
\text { Access to } \\
\text { medicinal plants }\end{array}$ & 5 & $\begin{array}{l}- \\
-\end{array}$ & & 1 & - & \\
\hline Bantu & $\begin{array}{l}\text { Peanut fields } \\
\text { Access to hunting } \\
\text { Fallowed field } \\
\text { (secondary for.) }\end{array}$ & $\begin{array}{l}4 \\
3 \\
7\end{array}$ & $\begin{array}{l}- \\
- \\
-\end{array}$ & & $\begin{array}{l}3 \\
2 \\
2\end{array}$ & $\begin{array}{l}- \\
- \\
-\end{array}$ & \\
\hline Timber company & $\begin{array}{l}\text { Logging } \\
\text { Bushmeat }\end{array}$ & $\begin{array}{l}1 \\
1\end{array}$ & - & & $\begin{array}{l}9 \\
7\end{array}$ & $\begin{array}{l}= \\
+\end{array}$ & \\
\hline $\begin{array}{l}\text { Conservation } \\
\text { Project }\end{array}$ & $\begin{array}{l}\text { Protection of } \\
\text { Gorillas }\end{array}$ & 10 & $=$ & & 3 & $=$ & \\
\hline
\end{tabular}

Under Interest:

Rank: 10 means that the stakeholder's activity/role in the forests supports SFM

1 means that his or her activity or role in the forest does not support it

Change: An estimate of the probability and direction of future change in the stakeholder's roles in SFM

Plus sign ( + ) means the stakeholders' activity will increasingly support SFM

Negative sign (-) means the stakeholders' activity will increasingly interfere with SFM

Equal sign $(\Rightarrow$ means the stakeholders' activity will not change 


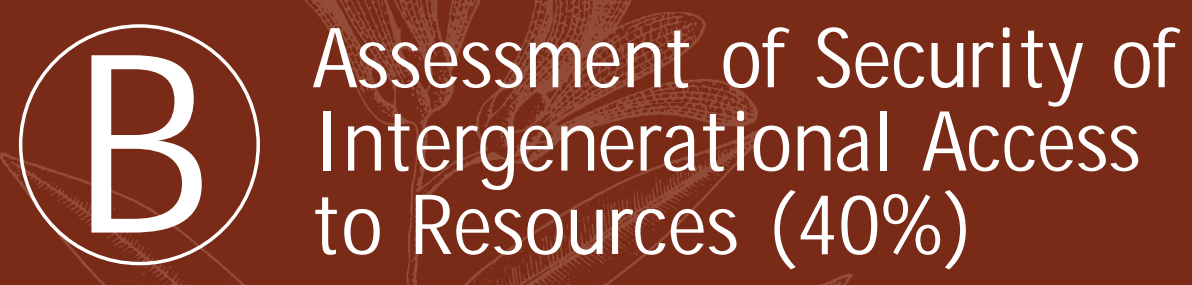


he allocation of 40 percentage points to this series of criteria and indicators reflects our conclusion that security of intergenerational access to resources ( $\mathrm{SIA} \mathrm{R}$ ) is a fundamental issue in sustainable forest management. This valuation reflects our perceptions that:

- continuing adequacy of forest resources is in the best interests of people who depend on those resources;

- people who have secure access to local forest resources, both for themselves and for their descendants, tend to take better care of those forests; and

- people who feel they are receiving a fair share of the benefits from forests are more likely to have a positive effect on those forests.

This percentage is not fixed, however, and assessors should adapt it as needed. Scoring assistance is available in The Scoring and A nalysis $G$ uide.

In the box, you will find a set of $C \&$ I pertaining to security of intergenerational access to resources. 


\section{PROPOSED PRINCI PLES, CRI TERI A AND INDICATORS ON SECURITY OF} I NTERGENERATI ONAL ACCESS TO RESOURCES

\section{P1 Forest management maintains or enhances fair intergenerational access to resources and economic benefits ( Total value $=\mathbf{4 0 \%}$ )}

C1.1 Local management is effective in controlling maintenance of and access to the resource.

I1.1.1 Ownership and use rights to resources (inter- and intragenerational) are clear and respect preexisting claims.

I1.1.2 Rules and norms of resource use are monitored and enforced.

11.1.3 Means of conflict resolution function without violence.

I1.1.4 Access to forest resources is perceived locally to be fair.

I1.1.5 Local people feel secure about access to resources.

C1.2 Forest actors have a reasonable share in the economic benefits derived from forest use.

11.2.1 Mechanisms for sharing benefits are seen as fair by local communities.

11.2.2 Opportunities exist for local and forest-dependent people to receive employment and training from forest companies.

1 1.2.3 Wages and other benefits conform to national and/ or International Labour Organisation (ILO) standards.

11.2.4 Damages are compensated in a fair manner.

I1.2.5 The various forest products are used in an optimal and equitable way.

C1.3 People link their and their children's future with management of forest resources.

11.3.1 People invest in their surroundings (e.g., time, effort, money).

I1.3.2 Outmigration levels are low.

I1.3.3 People recognise the need to balance numbers of people with natural resource use.

11.3.4 Children are educated (formally and informally) about natural resource management.

I1.3.5 Destruction of natural resources by local communities is rare.

I1.3.6 People maintain spiritual or emotional links to the land. 
For assessing this component (SIAR), the following three methods will be helpful: HistoEcological Matrix, Participatory Mapping, and A ccess to Resources by Generation (Pebble Distribution M ethod). ${ }^{13} \mathrm{We}$ discuss each in turn below:

\section{1 - HISTO-ECOLOGICAL MATRIX}

(adapted from Mt. Cameroon Proj ect and Anne Marie Tiani) ${ }^{14}$

PURPOSES

- To assess changes in the availability of different local resources over time, with projections of trends into the future (C riteria 1.1 and $\mathbf{1 . 3}$ ); and

- To shed light on resource use, regulation and access (C riterion 1.1)

PARTICI PANTS

Select groups of 5 to 10 participants, based first on the forest actor categories you identified earlier. In deciding how many groups you need, remember the importance of reflecting the views of men and women, the old and the young, the poor and the wealthy, and relevant local ethnic groups. Construct additional groups as needed. N ew locations may yield new differences that need to be included so be alert to this possibility.

\section{MATERI ALS}

You will be constructing a matrix. Ideally, you should have a large piece of paper on which a grid has been drawn - large enough for people to allocate pebbles (or some other convenient counter) among the cells. You will need 100 pebbles. $^{15}$

13 See also the pebble distribution method listed in Subsection C (below).

14 Kilum Mountain Forest Project, Northwest province, Cameroon also presented this method in a workshop there in November 1995.

15 Any small object of fairly uniform size is acceptable here. Diaw, for instance, used a nut; Sardjono's team, buttons; McDougall, dried corn; Porro and Porro, cocoa seeds. This is an opportunity for local creativity and adaptation! 


\section{METHODS}

The group will consist of your assessor team (one facilitator and one note taker) and the representatives of the particular forest actor group. Try to identify the dates of some significant local events in the area before the meeting so you can help those who are not adept at remembering dates. ${ }^{16}$

- Explain to the people that you are interested in understanding how their access to resources is changing over time.

- A sk the people in each group to list four resources in the area that are important to them. These will probably differ according to gender, ethnic group, etc.

- Prepare the matrix, with past dates (or relevant local events) at roughly 5-year intervals across the top, and important resources down the left margin. Include dates into the future (at least 5 years and 20 years). ${ }^{17}$

- Give the 100 pebbles to the group and ask them to distribute them through the years (using 100 pebbles for each row, or each resource), with the 100 pebbles representing that resource throughout time.

- A sk them to explain why they made the allocations they did and record this information, keeping in mind the $C \& I$ you are trying to assess. A Iso, record their pebble allocation on a sheet of paper, for later referral.

A s the people discuss these issues, try to keep the $C \& I$ in mind, jotting down evidence and case examples that pertain to the $C \& I$, for later entry into your master $C \&$ I spreadsheet. O ften, the most useful information for your

16 McDougall (1998) warns that the assessor should be clear on local history. Parts of the community she was assessing had moved from other areas, in some cases bringing the village name with them. This had to be sorted out before accurate results could be obtained.

17 Günter (1998), working in Trinidad, found his respondents dissatisfied with the pebble distribution approach, and used a questionnaire format instead. To get at the longitudinal aspects of sustainability, he asked 'What do you think was (is, will be) the total area of natural forests in Trinidad (in \% of total land area)? 1960 ? Today ? And 2040 ?' He concluded this series of questions by asking 'What is the basis for the estimate you have given: Redūced forest ārea or managēment restrictions?' (personal communication 12/97). 
assessment emerges as a side comment about which you did not know to ask. The results reflect people's perceptions of trends in resource availability. This makes it doubly important that assessors keep their opinions private, in order to minimise their influence on the results.

\section{TIME REQUIRED}

A verage of two hours training session for two facilitators. O ne half hour per group interview in which a matrix is filled in for the four resources.

ANALYSIS AND SCORING ${ }^{18}$

This requires a three-stage process. First, you must deal with the data from the pebble distribution. This will require entry of the pebble data into its own spreadsheet. There, you will record the pebble distribution data from each group. These data will show you the trends relating to the resources or products selected.

N ext, enter the list of $C \& I$ (in box above) into a spreadsheet (not your master spreadsheet). Consider the information you have noted down during the discussion. Type in a shorthand version of the cases and evidence that you have gathered under the appropriate criterion or indicator. For instance, if you have got information about local regulations, list that under Indicator 1.1.2. If the people mention activities like building churches or mosques, this would be an example of Indicator $\mathbf{1 . 3 . 1}$ (people investing in their surroundings). Be sure to record who/where the information came from.

Finally, score each case or bit of evidence from one (least conducive to sustainability) to ten (most conducive to sustainability). Enter the score for each bit of inforand Analysis Guide. 
mation on your master spreadsheet under the relevant criterion or indicator.

\section{SAMPLE MATRIX}

This sample matrix reflects an earlier version of this method in which we did not include future dates. It is important that you include at least two more columns with dates five years and twenty years hence. Porro and Porro (1998) consider six dates to be a practical maximum.

Table 1: Native Women Farmers

\begin{tabular}{lccccccccccc} 
Resource & $\mathbf{1 9 6 2}$ & 1967 & $\mathbf{1 9 7 2}$ & $\mathbf{1 9 7 7}$ & $\mathbf{1 9 8 2}$ & $\mathbf{1 9 8 7}$ & $\mathbf{1 9 9 2}$ & $\mathbf{1 9 9 7}$ & $\mathbf{2 0 0 2}$ & 2017 & Total \\
Palms & 2 & 4 & 8 & 13 & 15 & 17 & 19 & 22 & 100 & 100 \\
Beef & 25 & 22 & 20 & 15 & 8 & 5 & 3 & 2 & 100 \\
Egusi & 1 & 2 & 3 & 5 & 14 & 20 & 25 & 30 & \\
\hline
\end{tabular}

(adapted from Brocklesby et al. 1997) 


\section{2 - PARTICIPATORY MAPPING ${ }^{19}$}

PURPOSES

- To elicit people's perceptions of rights and responsibilities relating to local resources (C riteria $\mathbf{1 . 1}$ and $\mathbf{1 . 3}$ ); and

- To clarify how the local systems of resource management function (including rules, monitoring, sanctions, conflict resolution, etc.) (C riteria 1.1 and $\mathbf{1 . 2}$ )

\section{PARTICI PANTS}

Select groups of 5 to 10 participants, preferably with a mixture of different forest actors (including young and old, different ethnic groups and different occupations). G roups divided by gender work better, in our experience. The mapmaking exercise is often more informal and comfortable than the other methods, and the interplay of different perspectives can bring up important issues for assessment. Evaluate your experience, and see if there are categories of individuals who are silent (such as marginalised ethnic groups, lower castes). It may be necessary to have separate mapping exercises with them. Select different and more heterogeneous groups than selected for the $\mathrm{H}$ isto-ecological M atrix method.

\section{MATERI ALS}

The people can draw the maps on large pieces of paper, on transparency sheets ( for overlays of different issues), or simply on the ground (subsequently transferred to paper). Provide different coloured felt pens or some other tool with which to draw. Porro and Porro (1998) recommend the use of a camcorder or video recorder, if available and comfortable, for the participants.

19 For more discussions of participatory mapping, see Momberg et al. 1996; Stockdale and Ambrose 1996; Panday et al. 1997; J oint Forest Management Support Project 1992 (I and II); Molnar 1989; Bruce 1989, among others. 


\section{METHODS}

Your team will need a facilitator and a note taker. Remind the participants to keep in mind the $C \& I$ that you are trying to assess. One of the strengths of this method is its capacity to bring out issues that people may be reluctant to discuss. You are not concerned about accuracy of the map, but rather the identification of aspects of their management system and their view of their world. $\mathrm{H}$ ave relevant questions pertaining to security of tenure, management issues (like division of access, labour and control), and sharing of ben efits in mind, as you work with the local people to draw maps of their area. Sometimes, it is easier to start with an existing or simplified map to orient the participants. You will have to decide with the group how big an area to draw. It should be small enough to reflect their own management practices and those of others who have an important effect on their daily lives. If you have a camcorder, you can play back what you have recorded and get additional insights from the participants as they review what has been said.

\section{TIME REQUI RED}

Two hours of preparation by the facilitator and note taker; about two hours for each group.

ANALYSIS AND SCORING

Prepare a mapping spreadsheet, again with the relevant $C \& I$ listed. N ote down cases and evidence emerging from the mapping exercise that contribute to your assessment of the $C \& I$. Score them from one (least conducive to sustainability) to ten (most conducive to sustainability).

Take out the master list of $C \& I$ and consider the information you have noted down. Summarise the new information you have gathered as it relates to these $C \&$ I. For instance, if information about conflicts has surfaced, that might go under Indicator $\mathbf{1 . 1 . 3}$ and/or 1.2.1. Enter a short- 
hand version of this information with a score, on the master spreadsheet under the relevant criterion or indicator, noting the source as well.

\section{SAMPLE MAP}

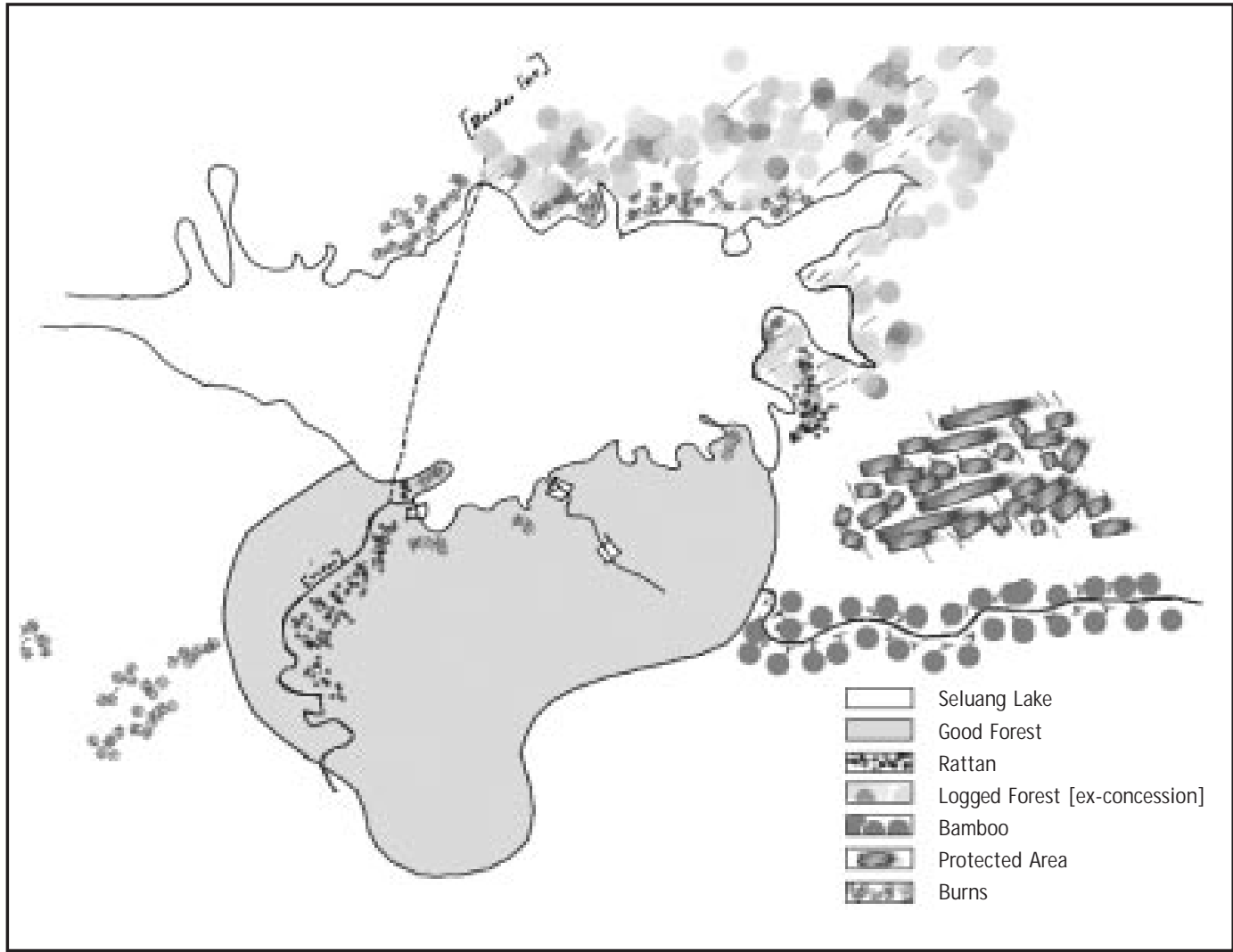

Map of the village territory of Danau Seluang on the eastern edge of Danau Sentarum Wildlife Reserve, West Kalimantan, Indonesia 


\section{3 - ACCESS TO RESOURCES BY GENERATION: PEBBLE DISTRIBUTION METHOD²0}

Sustainable forest management, by definition, includes an intergenerational element. In this method, we try to capture changes that are occurring and people's perceptions of those changes.

PURPOSES

- To assess the direction of change in resource accessibility in the area (C riterion 1.1); and

- To assess people's feelings of security about intergenerational access to resources (C riterion 1.3; Indicator 1.1.5).

\section{PARTICI PANTS}

Select 12-15 participants from each of the most important stakeholder groups in the area. ${ }^{21} \mathrm{Be}$ certain to use the method with approximately equal number of men and women and attend to other locally important social differences (age, ethnicity, etc.). W hether to conduct the pebble sorting individually or in homogeneous groups depends on local conditions and your experience to date with other methods in this area. In any event, if you work with groups, be sure to record the relevant demographic data (ages, gender distribution, ethnicity, occupation, etc.). Data reliability is improved if groups or respondents of similar age are put together - since perceptions about generations are related to the respondent's age.

20 Günter was dissatisfied with the pebble distribution approach, and again used a questionnaire format instead. To get at the intergenerational aspects of sustainability, he asked '... please give your opinion on how access to forest resources is changing over time per generation $(10=$ high, $1=(0 \mathrm{w})$ : 'Grandparents , self , and grandchildren..' He concluded by asking 'What is the basis for the estimate you have given: Reduced forest area or managēment restrictions?' (pers̄onal communication 12/97).

21

The purpose here is not to provide proportional representation of stakeholders, but rather to hear the views of the variety of kinds of forest actors in the area. 


\section{MATERI ALS}

See form shown below. Prepare 100 pebbles for distribution among the three categories: grandparents, yourself, grandchildren..$^{22}$ You can use plates or you can make cells on a large piece of paper for each generation. If 100 is too many pebbles to deal with, choose a smaller number ( 50 or 33 will still keep the arithmetic simple). Just be consistent.

METHODS

Explain why you are doing this. Tell your participant(s) that you are interested in understanding how local access to resources is changing over time and what he or she thinks about the future prognosis. ${ }^{23} \mathrm{~A}$ sk him or her to imagine all the forest resources over time (from the time of one's grandparents through the present to the time of one's grandchildren). ${ }^{24} \mathrm{H}$ aving respondents self-identify as belonging to one or another generation (including giving their ages) has been recommended. This will improve the complementarity of this with other methods related to time. This method is likely to provide valuable input on people's feelings of intergenerational security, as well as complementing the information available from the $\mathrm{H}$ isto-Ecological M atrices. Porro and Porro (1998) suggest using this generational method with regard to both changes in access to resources and in human well-being. 0 ne proviso: Clarify the migration history of the people. If the parental or grandparental generation came from a distant area, the implications for local conditions of their abundance/scarcity must be interpreted accordingly.

22 Sardjono et al. (1997) expanded to five categories: grandparents, parents, self, children, and grandchildren. Porro and Porro (1998) used parents, self, children, and grandchildren.

23 Tchikangwa et al. (1998) found the concept 'access to resources' difficult to translate into local languages. They substituted frequency of conflicts by generation as a proxy for security of access to resources. McDougall (1998) had a similar problem, explaining 'access' locally as 'abundance + quality of the resource + ability/permission to use'. criteria. But if comparisons among sites are desired, one interpretation or the other should be selected. 
It is important to explain to the people your interest in all forest resources, before they begin allocating pebbles to the generations. A sk participants to divide up the 100 pebbles among the generations (grandparents, self, grandchildren). Your participants can make qualitatively determined assessment of how many pebbles to put in each generation (then you must count them). Record the allocations on the form.

\section{TI ME REQUI RED}

This is one of the fastest methods we have tried, taking 1-2 minutes per person, if done individually, and 15-30 minutes for groups of 15 (Tiani et al. 1997). Sardjono et al. (1997) reported spending an average of 4 minutes per interview at one site and 6 minutes at the other; B rocklesby et al. (1997) spent an average of 7.8 minutes per interview. They spent four hours adapting the question to the area and $>4.8$ hours conducting the interviews ( 32 interviews with 77 individuals). Diaw et al. (1998) estimated 2 minutes per interview.

\section{ANALYSIS AND SCORING}

These data can be entered onto a generations spreadsheet ( see T he Scoring and A nalysis $\mathrm{G}$ uide) and analysed easily. The most straightforward analytical need is to determine how the distribution of pebbles varies by generation, on average. This will be more illuminating if you do the same analyses by participants' gender, ethnic group, occupation, and other categories you have determined to be relevant in your area.

Returning to C riterion 1.1, we can surmise that when the number of pebbles allocated to one's grandchildren is significantly less than those in one's own generation or in one's grandparents' generation, there is a problem with people's feelings of security about their children's access to resources. Such a finding may also indicate a real problem in 
maintaining the resources. It may also suggest that the respondents do not link their children's future with management of forest resources (C riterion 1.3). Differences among stakeholders, in terms of these perceptions, may be illuminating as well (with regard to issues of fairness - $\mathbf{I} \mathbf{1 . 2 . 1}$, on mechanisms for sharing benefits, I1.2.2, on employment; I1.2.4, on damages).

In Cameroon, Brocklesby et al. (1997) and Tiani et al. (1997, see below) found a real decrease in forest resources anticipated for the future - which would suggest a sustainability problem (perhaps a 3 , on our sustainability scoring system). Sardjono et al. 's (1997) results appear to show a much more optimistic view of the future (with a concomitantly higher score). 
SAMPLE GENERATIONAL FORM AND ANALYSES

\section{Access to Resources over Time - Pebble Distribution Method}

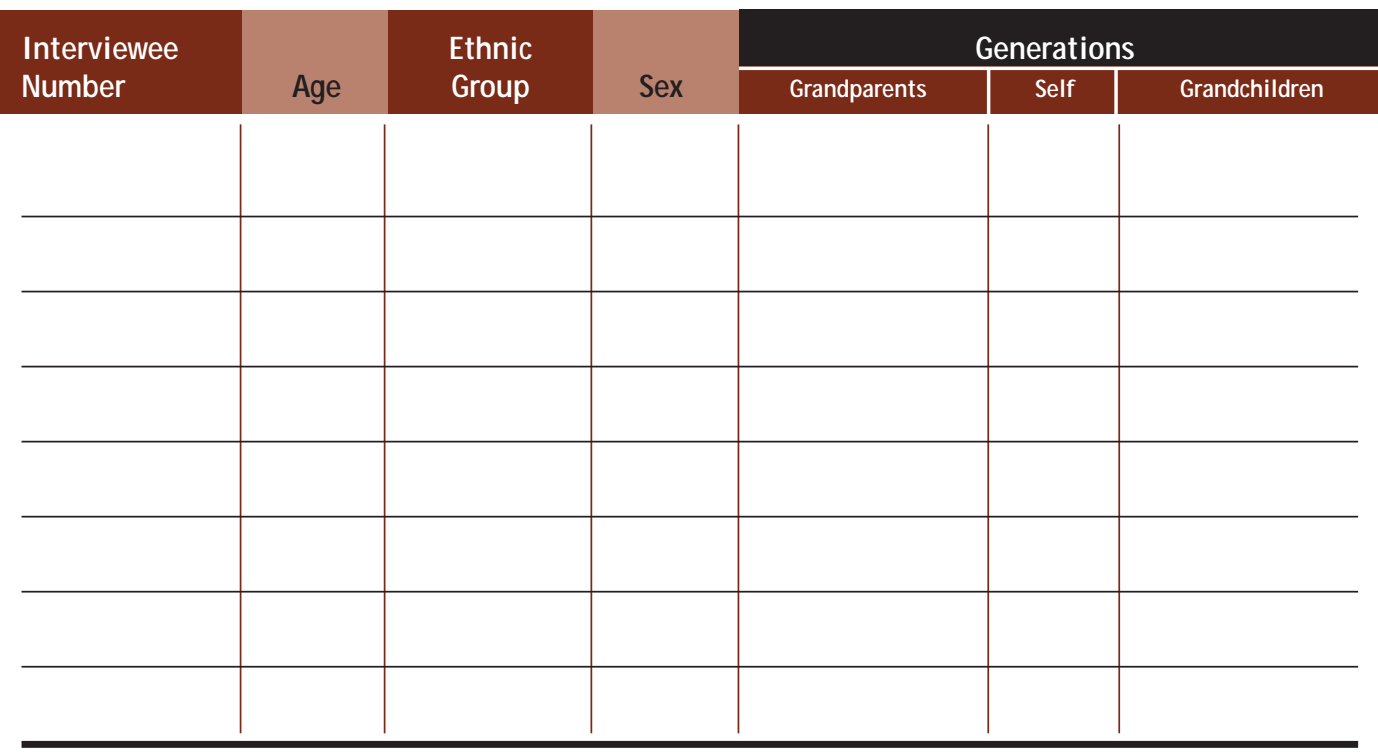

The first four columns are for the demographic data on which you will later want to sort.

The last three columns are for the distribution of the 100 pebbles (or percentage points). 
EXAMPLES OF ANALYSES OF THESE DATA:

Distribution of Pebbles over Generations, by gender and user group category

(Mt. Cameroon) - Brocklesby et al. 1997

\begin{tabular}{|c|c|c|c|c|c|c|}
\hline \multirow[b]{2}{*}{ Sex } & \multirow[b]{2}{*}{ Generation } & \multicolumn{5}{|c|}{ User Group } \\
\hline & & $\begin{array}{c}\text { CDC } \\
\text { worker } \\
(n=17)\end{array}$ & $\begin{array}{l}\text { Native } \\
\text { farmer } \\
(n=20)\end{array}$ & $\begin{array}{c}\text { Stranger } \\
(n-20)\end{array}$ & $\begin{array}{l}\text { Timber } \\
\text { Users } \\
(n-18)\end{array}$ & $\begin{array}{l}\text { Grand } \\
\text { Total }\end{array}$ \\
\hline Female & $\begin{array}{l}\text { grandparent } \\
\text { self } \\
\text { grandchildren }\end{array}$ & $\begin{array}{l}43 \\
34 \\
23\end{array}$ & $\begin{array}{r}72 \\
22 \\
6\end{array}$ & $\begin{array}{r}65 \\
26 \\
9\end{array}$ & $\begin{array}{l}56 \\
34 \\
10\end{array}$ & $\begin{array}{l}62 \\
28 \\
10\end{array}$ \\
\hline Male & $\begin{array}{l}\text { grandparent } \\
\text { self } \\
\text { grandchildren }\end{array}$ & $\begin{array}{l}53 \\
31 \\
16\end{array}$ & $\begin{array}{l}54 \\
29 \\
17\end{array}$ & $\begin{array}{l}57 \\
28 \\
14\end{array}$ & $\begin{array}{l}54 \\
31 \\
15\end{array}$ & $\begin{array}{l}54 \\
30 \\
16\end{array}$ \\
\hline Total & grandparent & 50 & 62 & 61 & 55 & 57 \\
\hline Total & self & 32 & 26 & 27 & 32 & 29 \\
\hline Total & grandchildren & 18 & 12 & 12 & 13 & 14 \\
\hline
\end{tabular}


EXAMPLES OF ANALYSES OF THESE DATA:

Access to Resources Over Time

(Adapted from Tiani et al. 1997)

\begin{tabular}{lccc} 
Generations & Female & Male & Average \\
Grandparents' & 24 & 25 & 25 \\
Parents' & 54 & 58 & 57 \\
Grandchildren's & 22 & 17 & 18 \\
\hline Total & 100 & 100 & 100 \\
\hline
\end{tabular}




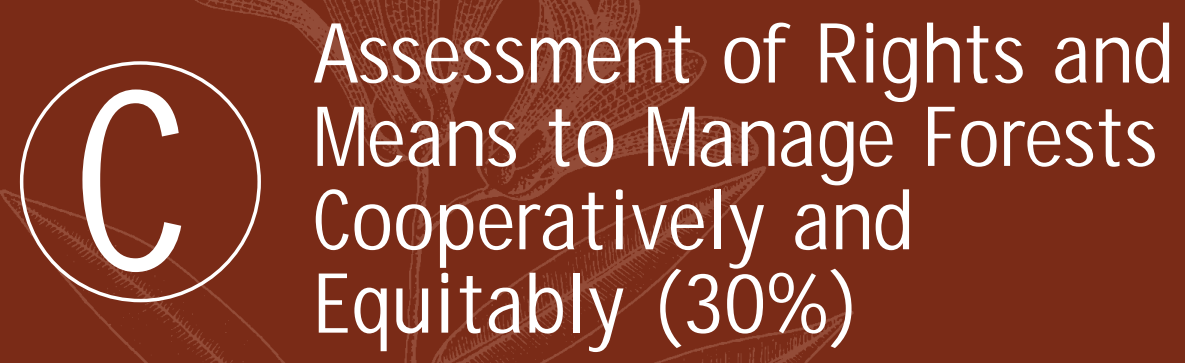


his principle, assessment of rights and means to manage cooperatively and equitably (see box), was initially phrased as a requirement for 'local people's participation' in forest management. A fter pre-testing a number of methods focused on measuring people's participation, we changed the wording to reflect the fact that in many of the world's forests, local people are already performing important, day to day, management functions (see, e.g., Colfer and Wadley 1996). The issue could, in many cases, be turned around to require the participation of timber companies in local management. W e, therefore, rephrased the issue in terms of 'rights and means to manage forests cooperatively and equitably' ${ }^{25}$

A s with the preceding section (B), our allocation of percentage points (30, in this case) includes both our previous experience and a significant el ement of judgement. We consider the issue of cooperative management important for the following reasons:

- Local communities often have valuable indigenous knowledge about the multiple uses of forests, otherwise unavailable to other stakeholders.

- Forest actors (typically local communities and workers) have the potential for both positive and negative effects on local forests, and attention to their interests enhances the probability that the positive effects will prevail.

- The dependence, poverty and powerlessness of forest actors places an ethical requirement that their needs be addressed by the typically more wealthy and powerful groups harvesting local resources.

O ne of the functions of people's having a voice in management - pointed out by Tchikangwa and

25 This principle has been phrased variously, including the phrases 'rights and responsibilities' (in place of 'rights and means'), 'to comanage forests equitably' (in place of 'to manage forests cooperatively and equitably'), 'Forest actors' (in place of 'Concerned stakeholders'). We recognise that the wording may continue to evolve. 
his 1996 C\&I assessment team (Prabhu et al. 1998) - is to ensure that they have the power or the capacity to protect and manage local resources (as described in the previous section on security of intergenerational access to resources).

A s with the previous section, our certainty about the universality of the following principles and criteria is greater than for the indicators. 
PROPOSED PRI NCIPLES, CRI TERI A AND I NDICATORS ON COOPERATIVE AND EQUITABLE MANAGEMENT OF FOREST RESOURCES

\section{P2 Concerned stakeholders have acknowledged rights and means to manage forests cooperatively and equitably ( Total value $=30 \%$ )}

C2.1 Effective mechanisms exist for two-way communication related to forest management among stakeholders.

12.1.1 $>50 \%$ of timber company personnel and forestry officials speak one or more local language, or $>50 \%$ of local women speak the national language.

12.1.2 Local stakeholders meet with satisfactory frequency, representation of local diversity, and quality of interaction.

12.1.3 Contributions made by all stakeholders are mutually respected and valued at a generally satisfactory level.

C2.2 Local stakeholders have detailed, reciprocal knowledge pertaining to forest resource use (including user groups and gender roles), as well as forest management plans prior to implementation.

12.2.1 Plans/maps showing integration of uses by different stakeholders exist.

12.2.2 Updated plans, baseline studies and maps are widely available, outlining logging details like cutting areas and road construction, and include temporal aspects.

12.2.3 Baseline studies of local human systems are available and consulted.

12.2.4 Management staff recognises the legitimate interests and rights of other stakeholders.

12.2.5 Management of NTFP reflects the interests and rights of local stakeholders.

C2.3 Agreement exists on rights and responsibilities of relevant stakeholders.

12.3.1 Level of conflict is acceptable to stakeholders. 
A s before, you will need to prepare a working spreadsheet for the method, followed by entry into the master $C \& \mid$ spreadsheet from the box above. A s before, you will be making ongoing estimates from 1 (unsustainable) to 10 (sustainable) for these $C \& I$.

To begin these assessments, you will want first to visit the timber company's local headquarters. Indicator 2.1.1, the ability of timber company personnel to speak local languages, will best be assessed there. Most of the indicators for Criterion $\mathbf{2 . 2}$ will be available there (e.g. Indicator 2.2.1, on the existence of plans and maps, Indicator $\mathbf{2 . 2 . 3 , ~ o n ~ b a s e l i n e ~ s t u d i e s ~ o f ~ h u m a n ~ s y s t e m s , ~ I n d i c a t o r ~} \mathbf{2 . 2 . 5}$, on management of NTFPS). Similarly, Indicator 2.2.2, on the availability of planning documents, maps and studies, will have to be sought out in villages. Make a preliminary estimate for each of these indicators, typing in the evidence or basis for your estimate.

For assessing the existence of shared rights and responsibilities for managing the forest, we suggest a more formal method: 'Rights/M eans to Manage' Pebble Distribution. It is important to remember that, while conducting this study, you will be interacting with local people and thus learning more, of a qualitative nature, about their situation. Don't waste this additional information. Enter it into the spreadsheet of $C \& I$ that you have prepared as evidence or cases. 


\section{1 - RIGHTS/ MEANS TO MANAGE: PEBBLE DISTRIBUTION²6}

PURPOSES

\section{PARTICI PANTS}

You will need 12 to 15 responses from each stakeholder, user group or social category you want to analyse. ${ }^{27}$ These will include, at least, men and women, different ethnic groups, different occupations. In Cameroon, it was important to include old, adult, and young. You want groups that have a clear relationship with forest management.

You may conduct the interviews in groups (5-15 people) or individually. If you decide to conduct group interviews, the groups should be fairly homogeneous (e.g., all women, all one ethnic group, all one occupation). You will need the usual demographic data about each respondent (age, sex, ethnic group, etc.) needed in your subsequent analyses recognising that different groups have different interests and biases that you must factor in, in interpreting their contributions.

In creating this method, we were influenced by the work of Ostrom (1994) and Gender Analysis and Forestry (1995). Our initial method included separate attention to 'means' to manage, but we concluded that the functions listed reflect the responsibilities of management adequately; and researchers felt there was significant duplication in the responses to 'rights' and 'means'.

27 Again, the purpose is not to get proportional representation, but rather to gain access to views of the diversity of forest actors in the area. 


\section{MATERI ALS}

Begin by collecting 100 pebbles. Prepare a matrix with large enough cells so that people can allocate the pebbles along the rows of the matrix. ${ }^{28}$ The rows list the functions of forest management (see below). The columns list the most important stakeholders (including but not limited to forest actors). Brocklesby et al. (1997) recommend including separate sub-columns for each gender; Porro and Porro (1998) recommend against it. It may be desirable to make separate forms pertaining to men's and women's roles in regard to these management functions, as a way to simplify the interview process. M ake a number of smaller, paper copies of the matrices, for use in recording the data you collect (Form A) ${ }^{29}$

Form B will require boxes for each stakeholder down the left side of the page, and spaces for notes pertaining to frequency of interaction among stakeholders, on the right.

Before beginning the meeting with your group, review the $C \& I$ listed in the box above, so that your information needs are clear in your own mind. Ideas and perceptions expressed as people discuss the form are likely to be as useful to you as the quantified results. Remember to record the demographic composition of your group (ethnicity, gender, age, occupation, etc.) for use in your subsequent analyses of the data.

\section{METHOD}

Identify three to five stakeholder groups with a significant role in forest management, ${ }^{30}$ based on your previous assessments (Section A). These stakeholder

28 Diaw et al. (1998) used plates rather than columns to represent the different stakeholders - allocating the 100 pebbles among the plates. Tiani et al. (1997) suggest asking respondents to 'grade' the stakeholders, using the 20 points used in Cameroonian schools, rather than 100 physical objects - which she felt required comprehension of too large a number and too much calculation.

29 Porro and Porro (1998) suggest merging Form A with the participatory cardsorting method (The Grab Bag); and concentrating effort on Form B.

Tiani et al. (1997), for instance, used the state, the local population, forest industry and artisans. Brocklesby et al. (1997) used indigenes, the Mount Cameroon conservation project, government officials, the timber company, and the Cameroon Development Corporation. Sardjono et al. (1997) selected two ethnic group, timber concessionaires and the government. 
groups will be entered on forms A and B (example below), and will also be represented in your sample of respondents (above).

Explain to your respondent/group that you are interested in understanding who they consider responsible for managing the forest in the area. $W$ ho is doing it now? The answer to this question about which you should be able to elicit information is W ho do local people think should have the rights to manage? Clarify in your own mind what forest is most relevant for your needs. Clarify what you mean by rights.

Explain that the rows represent different rights and responsibilities in forest management, and you want the participants to allocate these 100 pebbles among the stakeholders listed across the top. They will allocate the 100 pebbles, once for each row. They do not need to count the pebbles; qualitative estimates are adequate (but YOU will need to count the pebbles and enter the counts on the paper forms you have made).

\section{TIME REQUI RED}

Revising the form for your local situation and training fieldworkers should take about four hours. We anticipate that each interview will take less than an hour. Data entry and analysis should take about 5 hours.

\section{ANALYSIS AND SCORING ${ }^{31}$}

You will need to analyse the results by the stakeholder/user group or social categories you selected to interview. The different functions of forest management (lefthand column) will be averaged for each form to represent overall forest management. When you have conducted individual interviews, these means will then be transferred to a 'rights' spreadsheet where all the forms in a given group will again be averaged (e.g., all female respondents, all dayak respondents, or

31 Further guidance on analysis of these data is available in The Scoring and Analysis Guide. 
all timber company manager respondents). In this way, the average scores allocated to each stakeholder listed on the form (each column) can be compared across respondent groups. This will tell us whether or not there is agreement about rights and responsibilities ( $\mathbf{C}$ riterion $\mathbf{2 . 3}$ ), and whether or not the formal forest managers recognise the contribution of informal forest managers (Indicator 2.2.4).

You will be looking for a general pattern of agreement across respondent groups first ( for $\mathbf{C}$ riterion 2.3). You will then want to focus on the responses of the formal forest managers to see if they recognise the roles of other managers (Indicator 2.2.4). U se the same scoring pattern you used before (see below).

N ext, you can analyse Form B. W hat information have you collected on people's interactions (C riterion 2.1)? Do local communities interact regularly with timber company employees? A re there meetings among important stakeholders? A gain, keep focused on the indicators listed in the box above, and enter the evidence you collect from these interviews into your rights spreadsheet under the appropriate criterion or indicator. Make your assessment of sustainability (1-10) for each new bit of evidence.

The final step involves completing this section of the master spreadsheet. Enter your findings, both qualitative and quantitative, with an appropriate score, as you have done with the other methods: one for patterns that suggest a lack of sustainability (no agreement on roles, no respect for local contributions to forest management) and ten for the most sustainable patterns (agreement on roles and respect by formal managers for the balanced in put of other stakeholders). 
SAMPLE FORMS AND SAMPLE ANALYSIS

Form A - Rights/ Means to Manage Pebble Distribution Method

\begin{tabular}{|c|c|c|c|c|c|c|c|c|c|}
\hline \multirow{3}{*}{ Management functions } & \multicolumn{9}{|c|}{ Forest Managers } \\
\hline & \multicolumn{2}{|c|}{ Pygmies } & \multicolumn{2}{|c|}{ Bantus } & \multicolumn{2}{|c|}{ The State } & \multicolumn{2}{|c|}{ Timber Co. } & \multirow[t]{2}{*}{ Total } \\
\hline & M & $F$ & $M$ & $\mathbf{F}$ & M & $F$ & $\mathbf{M}$ & $\bar{F}$ & \\
\hline \multicolumn{10}{|l|}{$\begin{array}{l}\text { Defining/protecting } \\
\text { boundaries }\end{array}$} \\
\hline \multicolumn{10}{|l|}{$\begin{array}{l}\text { Developing/ applying } \\
\text { rules/ regulations }\end{array}$} \\
\hline \multicolumn{10}{|l|}{ Monitoring compliance } \\
\hline \multicolumn{10}{|l|}{ Resolving conflicts } \\
\hline \multicolumn{10}{|l|}{$\begin{array}{l}\text { Providing leadership/ } \\
\text { organisation }\end{array}$} \\
\hline \multicolumn{10}{|l|}{$\begin{array}{l}\text { Assessing fines/ } \\
\text { sanctions }\end{array}$} \\
\hline Sums & $\begin{array}{l}\text { sum } \\
600\end{array}$ & $\begin{array}{l}\text { sum } \\
600\end{array}$ & $\begin{array}{l}\text { sum } \\
600\end{array}$ & $\begin{array}{l}\text { sum } \\
600\end{array}$ & $\begin{array}{l}\text { sum } \\
600\end{array}$ & $\begin{array}{l}\text { sum } \\
600\end{array}$ & $\begin{array}{l}\text { sum } \\
600\end{array}$ & $\begin{array}{l}\text { sum } \\
600\end{array}$ & \\
\hline
\end{tabular}

Apportion the rights and responsibilities to manage to each manager depending on the management issues on the left. Divide the pebbles or percentage points among the stakeholders (along the row), dividing between males (M) and females (F). It will probably be necessary to have some locally relevant examples in mind. 
In the following example, females and males from the Dja Reserve allocated pebbles among the stakeholders listed on the left (Government, County, etc.). These allocations (represented by pebbles distributed among stakeholders for each of the six functions listed in the above form) were then averaged, to provide an overall assessment of 'rights to manage'. This kind of analysis can be done by gender (as below), by ethnic group, by age, or any other relevant demographic characteristics.

\section{Gender Differences of Opinion on Rights to Manage the Forest (Dja Reserve)}

\begin{tabular}{lccc} 
Stakeholder & $\begin{array}{c}\text { Female } \\
(\mathrm{n}=22)\end{array}$ & $\begin{array}{c}\text { Male } \\
(\mathrm{n}=19)\end{array}$ & Mean \\
\hline Government & 43 & 35 & 39 \\
County & 12 & 16 & 14 \\
Dev. Agency & 5 & 4 & 5 \\
Logging Company & 2 & 0 & 1 \\
Elders Group & 13 & 21 & 17 \\
Kako & 7 & 6 & 7 \\
Nzime & 13 & 11 & 12 \\
Baka & 6 & 6 & 6 \\
\hline
\end{tabular}

Rows with shading and italic font indicate there was disagreement between female and male, according to the Mann-Whitney Test with $\alpha=0.05$. 


\section{SAMPLE FORMS AND SAMPLE ANALYSIS}

\section{Form B - Levels of Interaction}

\section{Stakeholder \\ Reason for Interaction}

Kenyah and $\log$ Co.

Log Co. and Kenyah

Log Co. and Kutai

Kutai and Log Co.

Gov't and Log Co.
The company made a road through a village pineapple field; Kenyah seeking recompense - had two meetings.

The company wants the Kenyah to plant Acacia mangium to support the company's plantation development plans - regular visits from the company, every week or two.

The company is displeased with the Kutai's cutting of merchantable logs - rumours that the company may call in the police.

A Kutai girl (Muslim) became pregnant by one of the Christian loggers from one of the eastern islands - rumours emphasising conflict, potential explosiveness of issue.

The government suspects foul play in the paying of logging fees; this problem is somehow resolved without additional formal fee payments by the company - local suspicions of collusion/bribes.

$\begin{array}{ll}\text { Description of group: } & \text { (Include gender, age, ethnic and occupational distribution at least) } \\ \text { Eight Kenyah women farmers, ranging in age from 18-45 }\end{array}$

( This is an imaginary example) 
Assessment of
Remaining I ssues
$(30 \%)$ 
he $C \&$ I listed below (see box) have not been the focus of CIFO R methodological development and testing, to date. However, they represent a partial synthesis of previous field test results on social $C \& I$ - those remaining after 'security of intergenerational access to resources' and 'rights and responsibilities to manage forests cooperatively and equitably' have been addressed. Because we consider them to be important components in human well-being, we have included them below, with some ideas on how one might be able to assess them. 
PROPOSED PRI NCI PLES, CRI TERI A AND I NDICATORS ON HEALTH OF FOREST ACTORS, CULTURES, AND THE FOREST

\section{P3 The health of forest actors, cultures and the forest is acceptable to all stakeholders (Total value $=30 \%$ )}

C3.1 There is recognisable balance between human activities and environmental conditions.

13.1.1 Environmental conditions affected by human uses are stable or improving.

13.1.2 Inmigration and/or natural population increases are in harmony with maintaining the forest.

C3.2 The relationship between forest management and human health is recognised.

13.2.1 Forest managers cooperate with public health authorities regarding illnesses related to forest management.

13.2.2 Nutritional status is adequate among local populations (e.g. children's growth conforms to international standards of height for weight; infant and $<5$ year mortality levels are low). ${ }^{3}$

13.2.3 Forest employers follow ILO work and safety conditions and take responsibility for the forestrelated health risks of workers.

C3.3 The relationship between forest maintenance and human culture is acknowledged as important.

13.3.1 Forest managers can explain links between relevant human cultures and the local forest.

13.3.2 Forest management plans reflect care in handling human cultural issues.

13.3.3 There is no significant increase in signs of cultural disintegration.

Return to the master $C \&$ I spreadsheet. A s with the other principles, criteria and indicators, keep these $C \& I$ in mind while you are conducting the methods outlined in the previous sections. If you are alert to these issues, you will find that you continually learn more about them in your conversations with local people, with timber company and in your daily observations.

32 The fact that this indicator is not necessarily related to its criterion is one example of the shortcomings in this third principle, due to the absence - in contrast to the first two principles - of systematic field testing. 
For C riterion 3.1, you will have to use considerable judgement. There is, for instance, a wide range of impacts that shifting cultivation (the most common agricultural form in tropical areas where logging companies operate) can have on local environments. ${ }^{33}$ In many of the areas where we have worked, shifting cultivation has been benign, with long fallow periods and complex agroforestry systems. In some areas, shifting cultivation can be a destructive land use (particularly where in-migrants without a forest use tradition have recently settled - 'shifted cultivation'). It is not always advisable to believe what you hear. Look for yourself.

For Indicator 3.1.1, check out the fallow length; see if there is a complex traditional system (with names for different stages of forest regrowth, and a different repertoire of products collected or managed in these stages); determine people's dependence on the forest (there may be important nutritional implications related to hunting, fishing and the gathering of forest products described as 'wild').

For Indicator 3.1.2, local health and government officials may have relevant information.

For $\mathbf{C}$ riterion 3.2, on the relationship between forest management and human health, spend time with timber company personnel and in logging sites. For Indicator 3.2.1, talk with both timber company personnel and local health officials. For Indicator 3.2.3, observe the actual behaviour of timber workers (are they wearing hard hats in dangerous areas or not? Do they use protective shoes while logging or not?) Indicator $\mathbf{3 . 2 . 2}$, on the other hand, will require time spent in health centres and/or observing in local villages.

33 For an excellent overview of some of the issues pertaining to shifting cultivation, see Warner (1991). 
For C riterion 3.3, on the relationship between forest maintenance and culture, talk with both local people and with timber company personnel. The most common situation we have encountered was a comparative lack of knowledge of and respect for the cultures of local people by timber company personnel and government forestry personnel. W ithout such knowledge and respect, cooperative management will be difficult, as will the attempt to maintain the forest resource over time.

Indicator 3.3.1, dealing with formal managers' knowledge and understanding, will definitely have to be assessed where there are timber company employees working (base camp or in the forest cutting areas). Indicator 3.3.2, on the incorporation of such knowledge into management plans, will require both examination of the plans, and assessment of the plans' implementation. Did this integration actually happen on the ground?

Indicator 3.3.3, on the level of cultural integrity, will require discussions with local people. You can also make use of local health centres and information from government offices of various kinds to make this assessment. Changes in the number of crimes, arrests, school leavings, outmigration, inter-ethnic conflicts are all examples of possible indicators that cultural integrity may be suffering. 
Scoring Procedure 
ou should now have a large spreadsheet with all three principles, and their C \& I, listed. Beside each indicator, there should be evidence or cases, each with a sustainability score ( 1 for most unsustainable to 10 for most sustainable).

I dentify which $C \& I$ do not have any evidence for making an assessment, or score, attached to them. See if you can fill any remaining holes ( either by a special trip to make a fresh assessment, by examination of your own memory and understanding of the overall situation, or by discussing it with other team members). Examine your evidence critically and be sure you only include real evidence in your computations.

For each indicator, compute the average of the scores you have given for each bit of evidence or case example. This will give you an average score for each indicator.

$\mathrm{N}$ ow, compute the average of the scores you have given for each indicator under each criterion. This will give you a series of average scores, one for each criterion. You can now assess the degree to which each of the criteria has been met, within each principle.

To assess each principle, you can then average the scores for each criterion within that principle. You can then say, for instance, that the overall average sustainability score for security of intergenerational access to resources is 7 ... perhaps.

The final step will be to make your overall assessment of human well-being. H uman well-being will be measured by computing an overall average of the criteria 
within each principle (see previous step), then multiplying that average by the percentage points allocated for that principle (e.g., if the average score for the criteria on SIA R (principle 1) is 6 , you would multiple $6 \times 0.4)$. The resulting scores for the three principles are subsequently added together, to provide a summative score on human well-being. A n overall score 1-3 is unacceptable. A score of 4-6 is acceptable. A score of 7-10 is good. H owever, if there are any individual criteria with average below 3, this constitutes a 'red flag' and managers should make serious efforts to improve their management in this area - even if overall average scores are within the acceptable range.

Remember that this combination of social $C \& I$ (all three principles) represents one-third of the total forest assessment (the other two-thirds relating to ecology and conventional forest management).

1. Forest management maintains or enhances fair intergenerational access to resources and economic benefits. (Total value $\mathbf{= 4 0} \%$ )

2. Concerned stakeholders have acknowledged rights and means to manage forest cooperatively and equitably. (Total value $\mathbf{= 3 0} \%$ )

3. The health of forest actors, cultures and the forest is acceptable to all stakeholders. (Total value $\mathbf{= 3 0} \%$ ) 
Glossary 
C riterion

D ependency

Forest actor

Forest/culture integration

Indicator

L ocal knowledge
Criteria are the intermediate points to which the information provided by indicators can be integrated and where an interpretable assessment crystallises (Prabhu et al. 1996).

Some stakeholders depend on the forest for their very livelihoods. They may hunt, fish, gather foods, medicines, fibres, timber and/or practice agroforestry. The resource base for people's microeconomic system has important implications for human well-being and, in turn, for the forests.

O ne of the categories of stakeholders identified as important for timber companies to be concerned about in their management; people who count in sustainable forest management ( $C$ olfer et al. 1999).

Cultures, or ways of life, tend to be intimately linked to their environments; forest communities are no exception. There may be sacred sites within the forest, symbolic systems that give meaning to life and are intimately tied to people's sense of self, security functions of forest plants during times of scarcity and myriad other connections.

A ny variable or component of the forest ecosystem of the relevant management system used to infer attributes of the sustainability of the resources and its utilisation (Landres 1992; Prabhu et al. 1996).

Those who have lived in forested areas often have unique and useful knowledge, based on long-term, local experience, that can be used in improving forest management, and in granting people a voice in their future. 
N T FPs

Poverty

Power deficits

Pre-existing rights

Principle

Proximity to the forest

Stakeholder
N on-Timber Forest Products (also sometimes called 'non-wood forest products').

People whose standard of living is extremely low require special attention, since they are proof of a problem with 'human wellbeing'.

People who live in and around the forest often have comparatively little power vis-à-vis other stakeholders. W here such powerlessness does exist, it may adversely affect both the people and the forest, since the people will not have the means to protect their resources.

In many commercial forest areas, there may be conflicting paradigms of what land ownership and use should mean. Sometimes communities that have occupied a given area for a long time have had their traditional rights usurped or severely compromised in recent times. Both justice and pragmatism suggest that these claims need to be respected.

A fundamental truth or law as the basis of reasoning or action. (O xford D ictionary of C urrent English 1987; Prabhu et al. 1996).

People living in or near the forest have a greater opportunity to affect the forest and be affected by it. The exact meaning of proximity will, of course, vary by location, depending on the quality of transportation and infrastructure.

Person or group with an interest in the forest. 
Sustainable forest management A way of dealing with the forest that maintains or enhances ecological functions and human well-being.

U ser group

Identifiable individuals who share a way of using the forest (e.g., hunters, bark collectors, forest farmers, NTFP marketers).

Verifier

Data or information that enhances the specificity or the ease of assessment of an indicator (Prabhu et al. 1996). 
Bibliography 
Brocklesby, M.A., Etuge, P., N tube, G., A labi, J., A nje, M., Bau Bau, V. and Molua, J. 1997. CIFOR $C$ ameroonian test of social methods for assessing criteria and indicators for sustainable forest management. Mt. Cameroon Project, Limbe, Cameroon. CIFOR Report, CIFOR, Bogor, Indonesia.

Bruce, J.W. 1989. Community forestry: rapid appraisal of tree and land tenure. FA O, Rome.

Colfer, C.J.P. 1995. W ho counts most in sustainable forest management. CIFOR Working Paper N 0. 7. CIFOR, Bogor, Indonesia.

Colfer, C.J.P. 1997. A test of social science assessment methods. CIFOR methods testing manual. CIFOR, Bogor, Indonesia.

Colfer, C.J.P. and W adley, R.L. 1996. A ssessing "participation" in forest management: workable methods and unworkable assumptions. CIFOR Working Paper No. 12. CIFOR, Bogor, Indonesia.

Colfer, C.J.P. with Prabhu, R. and W ollenberg, E. 1995. Principles, criteria and indicators: applying O ckham's Razor to the people-forestry link. CIFOR Working Paper No. 8. CIFOR, Bogor, Indonesia.

Colfer, C.J.P., Wadley, R.L., W oelfel, J. and H arwell, E. 1997a. From heartwood to bark: Indonesian gender issues in sustainable forest management. Women in $\mathrm{N}$ atural Resources 18: 7-14.

Colfer, C.J.P., W adley, R.L., H arwell, E. and R. Prabhu. 1997b. Intergenerational access to resources: developing criteria and indicators. CIFOR W orking Paper N 0. 18. CIFOR, Bogor, Indonesia.

C olfer, C.J.P., W oelfel, J., W adley, R.L. and H arwell, E. 1996b. A ssessing people's perceptions of forests in Danau Sentarum Wildlife Reserve. CIFOR Working Paper No. 13. CIFO R, Bogor, Indonesia.

Colfer, C.J.P. with Prabhu, R., G ünter, M., M cDougall, C., Porro, N .M . and Porro, R. 1999. W ho counts most? A ssessing human well-being in sustainable forest management. Criteria \& Indicators Toolbox Series N 0. 8. CIFOR, Bogor, Indonesia.

Diaw, C., Oyono, R., Sangkwa, F., Bidja, C., Efoua, S. and N guiebouri, J. 1998. Social science methods for assessing criteria and indicators of sustainable forest management: a report of the tests conducted in $\mathrm{C}$ ameroon humid forest benchmark and in the Lobe and N tem River basins - Part 1. CIFOR Report. CIFOR, Bogor, Indonesia. 
Federal M inistry for Environment, Youth and Family. 1996. Testing of criteria and indicators of sustainable forest management within the international CIFOR project. Federal Environment A gency, Vienna.

FA O . 1995. G ender A nalysis and Forestry. Forests, trees and people programme, Rome.

Günter, M . 1998. Intergenerational equity and sharing of benefits on an island state. Prepared for inclusion in: Colfer (ed.) Local people in logged forests: Well-being under scrutiny. CIFO R, Bogor, Indonesia.

IU C N . 1997. Beyond fences: seeking social sustainability in conservation. Volume 2: a resource book. IU CN, Gland.

Joint Forest M anagement Support Project. 1992. Field methods manual I and II. Society for Promotion of W astelands Development, $\mathrm{N}$ ew Delhi.

Landres, P.B. 1992. Ecological indicators: Panacea or liability. In: D.H. McKenzie, D.E. H yatt and J.E. McDonald (eds), Ecological Indicators, Volume 2, pp. 1295-1318. Elsevier A pplied Science, London.

M CD ougall, C. 1998. Final test of the social science methods, Bulungan, East Kalimantan. CIFOR Report. CIFOR, Bogor, Indonesia.

M olnar, A . 1989. Community forestry: rapid appraisal. Community Forestry N ote 3. FA O, Rome.

M omberg, F., A to, K. and Sirait, M . 1996. Drawing on local knowledge: a community mapping training manual: case studies from Indonesia. Ford Foundation, Yayasan Karya Sosial Pancur Kasih, and W W F, Jakarta, Indonesia.

M ount C ameroon Project. 1996. Stakeholder analysis for participatory resource management. Community Development Dept., Forest M anagement Dept., and M IN A GRI staff, Limbe, Cameroon.

O strom, E. 1994. N either market nor state: governance of common-pool resources in the twenty-first century. International Food Policy Research Institute, Washington, DC.

Oxford Dictionary of Current English. 1987. Oxford U niversity Press, N ew York.

Pandey, D.N ., C hadha, S., Chatterjee, A ., Swarz, A . and Poffen berger, M . 1997. Participatory mapping for joint forest management inventory, planning, and monitoring: methods manual (Volume Three). A sia Forest Network, Berkeley and $\mathrm{New}$ Delhi. 
Porro, R. and Porro, N .M. 1998. M ethods for assessing social science criteria and indicators for the sustainable management of forests: Brazil test. CIFO R Report. CIFOR, Bogor, Indonesia.

Prabhu, R., C olfer, C.J.P., Venkateswarlu, P., Tan, L.C., Soekmadi, R. and Wollen berg, E. 1996. Testing criteria and indicators for the sustainable management of forests: Phase I final report. CIFOR Special Publication. CIFO R, Bogor, Indonesia.

Prabhu, R., M aynard, W., Eba'a A tyi, R., C olfer, C.J.P., Shepherd, G., Venkateswarlu, P. and Tiayon, F. 1998. Testing and developing criteria and indicators for sustainable forest management in $\mathrm{C}$ ameroon: the Kribi test - Final report. C\&I Tool box. CIFOR, Bogor, Indonesia.

Prabhu, R., Haggith, M ., Purnomo, H., Rizal, A ., Sukadri, D ., Taylor, J. and Yasmi, Y. 1999. CIM AT (Criteria and indicators modification and adaptation tool). C riteria \& Indicators Toolbox Series N 0. 3. CIFO R, Bogor, Indonesia.

Sardjono, M.A ., Rositah, E., Wijaya, A . and A ngie, E.M . 1997. A test of social science assessment methods concerning indicators and criteria for sustainable forest management in East Kalimantan. CIFO R Report. CIFOR, Bogor, Indonesia.

Stockdale, M . and A mbrose, B. 1996. M apping and NTFP inventory: Participatory assessment methods for forest-dwelling communities in East Kalimantan, Indonesia. In: J. C arter (ed.), Recent approaches to participatory forest resource assessment, pp. 170-211. Rural Development Forestry Study Guide 2. ODI, London.

Tchikangwa, B.N. with Sikoua, S., M etomo, M. and A djudo, M.F. 1998. Test des méthodes en sciences sociales de vérification des critères et indicateurs d'aménagement durable des forêts: périphérie est de la Réserve du Dja (Sud-C ameroun). CIFOR Report. CIFOR, Bogor, Indonesia.

Tiani, A .M ., with M vogo Balla, E., O yono, A . and Kenmegne Diesse, E. 1997. A test of social science assessment methods (near M balmayo, Cameroon). Report to CIFOR, A ssessing Sustainable Forest Management: Testing Criteria and Indicators Project, M balmayo. CIFOR Report. CIFOR, Bogor, Indonesia.

Warner, K. 1991. Shifting cultivators: local technical knowledge and natural resource management in the humid tropics. Community Forestry $\mathrm{N}$ ote 8 . FA 0 , Rome. 
The Basic Assessment Guide for Human Well-Being (or The BAG focuses on the social criteria and indicators for sustainable forest management, a topic that has been the subject of considerable controversy and uncertainty. It is designed for people interested in assessing sustainable forest management, but who do not have a high degree of expertise in social sciences. The six simple methods described in this manual are designed for use by biophysical scientists with a college education. They can also be used by assessors with higher levels of expertise in social sciences, but they are presented in a 'cookbook' format. The Scoring and Analysis Guide, meant to be used with The BAG provides additional help in making assessments of human well being, including a specific scoring method. It also provides increasingly detailed levels of guidance in analysis.
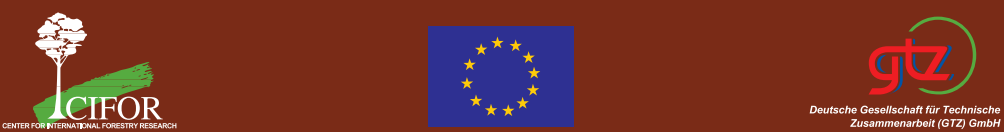